\title{
An overview of managing patients with coronaryheart disease and its pathogenesis: Antiplatelet and/or anticoagulation therapy for uneventful non-cardiac surgery
}

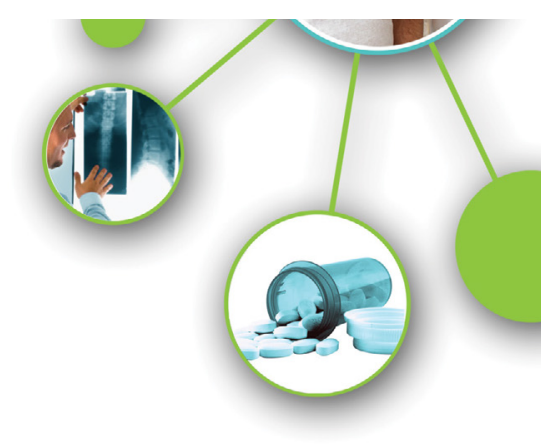

\begin{abstract}
Over the years, due to the high mortality rate among heart patients, the disease has received much attention and has led to many trials and studies on the disease and, of course, at a high cost. This article provides an overview of the pathophysiology, diagnostic methods and, ultimately, new therapies that have been the achievements of scientists over the past decades to date. And because of the large number of myocardial infarction during non-cardiac surgery in the cardiac patients, we review the latest recommendations for reducing the incidence of myocardial infarction and cardiac death during the non-cardiac surgery.
\end{abstract}

Keywords: coronary artery disease, stable ischemic heart disease, acute coronary syndrome, st. segment elevation myocardial infarction, non st. elevation myocardial infarction, non-cardiac surgery

\section{Introduction}

Coronary artery disease statistics are increasing. On the other hand, the advancement of science in the treatment and utilization of coronary artery bypass grafts and angioplasty, as well as various therapeutic cares, has prolonged life expectancy for heart patients whilst simultaneously increasing the number of noncardiac operations in heart patients. However, the global number of non-cardiac surgeries is estimated to be around two million cases a year, with cesarean sections accounting for one-third of these cases. How we deal with heart disease patients depends on how well we know the patient's past history. How thoroughly we review all patient records including angiographic, angioplasty stenting films and written records, considering the number and length and type of stents used even knowing the timing of a heart operation and possible peri procedure complications. Ultimately using risk assessment techniques to minimize the potential surgical risks. Considering all mentioned points are too crucial. As to what the medications should be and for how long they are to be taken, including antiplatelet and anticoagulants drugs, the risk of stent thrombosis when discontinued before operation is taken into account, and how much of this risk there is should be considered because the cases of stents or grafts thrombosis are a disaster that causes perioperative myocardial infarction. The major problem with myocardial infarction during non-cardiac surgery is that it is often asymptomatic, and therefore, accompanied by more than fifty percent fatality in this context.

In this article, we broadly review the latest findings on the pathophysiology, diagnosis and different treatment modalities of coronary artery disease. At the end of this article, we discuss introducing different manners to reduce the incidence of myocardial infarction in noncardiac operations.

\section{Epidemiology}

In developed countries, with the improvement of preventive methods and significant advances in the treatment of diseases, in general, we are faced with an increase in the population of older ages. At the same time, the number of atherosclerotic diseases that affect the coronary arteries is increasing in industrial societies with increasing age, although women lag behind men by 10 years [1]. The 2016 Heart Disease and Stroke Statistics update of the American Heart Association (AHA) has reported that 15.5

\section{Mohammadbagher Sharifkazemi*}

Department of Cardiology, Nemazee Hospital, Shiraz University of Medical Sciences (SUMS), Iran

*Author for correspondence: dr.sharifkazemi@gmail.com 
million American people over the age of twenty suffer from Coronary Heart Disease (CHD), which is estimated to cause an Acute Myocardial Infarction (AMI) every 42 seconds in an American person, causing one third of deaths in people over the age of thirty-five years [2]. In general, the leading cause of death in adults in low-, middle- and high-income countries is CHD [3].

Because in epidemiologic studies clinical symptoms play a major role in screening, these estimates are lower figures than reality. Hence, the results of autopsy studies are more realistic. For instance, in a 1992 study of 2,562 individuals between the ages of 20 and 59 from Minnesota in the US who had undergone autopsies, the prevalence of $\mathrm{CHD}$ in men was $32 \%$ and in women $16 \%$ [4]. In recent decades, and in developed countries, the outbreak of CHD due to atherosclerosis has declined substantially; however, it is growing in developing countries [5]. Of course, the factors affecting the prevalence of atherosclerosis are numerous and, therefore, in different societies we have a different outbreak rate of CHD and death because of it. In a fascinating study over Canadian immigrants, the highest risk of atherosclerosis was in Asian (excluding Chinese immigrants) and European populations, while the lowest risk was for Chinese immigrants $[6,7]$. In Europe, four million deaths per year are due to Cardiovascular Disease (CVD), including $\mathrm{CHD}$ and stroke, causing close to half of all deaths. Even at the level of European countries, there is also a large geographic death rate inequality; higher CVD mortality, as well as premature CVD mortality in the Eastern European countries such as Russian Federation, compared to a country like France in Western Europe [8].
Although numerous studies of an autopsy on soldiers killed in the Vietnam War in 1953 have shown that the onset of illness begins in young adults, differences in the prevalence of atherosclerosis are seen in the reports published over the past sixty years. As a whole, it can be said that in the developed countries, with the exception of the 1990s, there is a downward trend in its prevalence, although this finding is not unanimous in all studies TABLE 1 [4,9-15].

\section{Cost-effectiveness and economic burden of atherosclerosis}

From another perspective, the budget impact of Disability-Adjusted Life Years (DALY); measure of years of life lost due to death from a condition, and years lived with disability due to a condition at work, is very important [16]. To clarify the burden on the different aspect, we should consider a few examples; the length of hospital stays of an AMI patient with an average of 10.3 days in Germany and the cost of performing an uneventful coronary PCI in the United States is $\$ 21,204$. More generally, for healthcare of CVD patients in the United Kingdom at a rate of $£ 6.8$ billion, and in the United States the $\$ 320$ billion contributes annually [17], would make it possible to look at the other problems around the cardiovascular patients. Therefore, cardiovascular prevention programs reduce the burden of DALY, and more effective treatments to decline the death of cardiac patients, have long been considered by government treatment systems. International leaders have called for contributing global cardiovascular preventive projects in developing countries [18] and in 2012, at the World Health Assembly, adopted the global target of $25 \%$ reduction in mortality due to non-

TABLE 1. Autopsy proven prevalence of atherosclerotic involvement of coronary arteries in different studies during the past four decades $[4,9-15]$.

\begin{tabular}{|l|l|l|l|l|l|}
\hline Method & $\begin{array}{l}\text { Number of } \\
\text { cases }\end{array}$ & Period & Age range & $\begin{array}{l}\text { Prevalence of } \\
\text { Atherosclerosis in men }\end{array}$ & $\begin{array}{l}\text { Prevalence of } \\
\text { Atherosclerosis in women }\end{array}$ \\
\hline Olmsted County residents & 2,562 & $1979-1983$ & $16-64$ & $42 \%$ & $29 \%$ \\
\hline & & $1990-1994$ & & & \\
\cline { 3 - 6 } & & $18-59$ & $32 \%$ & $16 \%$ \\
\hline US military personnel & 3,832 & $2001-2011$ & $18-59$ & $12.10 \%$ & N/A \\
\hline Died from non-cardiac trauma & 111 & $1988-1989$ & $26+/-6$ & $78.30 \%$ & N/A \\
\hline Korean Soldiers Victims & 300 & $1947-1972$ & $18-48$ & $77.30 \%$ & N/A \\
\hline Vietnam Soldiers Victims & 105 & 1971 & $\mathrm{~N} / \mathrm{A}$ & $45.00 \%$ & N/A \\
\hline IVUS in heart donors for transplantation & 262 & 2001 & $33.4 \pm 13.2$ & $52.00 \%$ & N/A \\
\hline $\begin{array}{l}\text { Serial computed tomography scans for } \\
\text { calcium scoring (MESA study) }\end{array}$ & $1062-4837$ & $2000-2012$ & $55-84$ & $52.00 \%$ & $57.14 \%$ \\
\hline Unnatural deaths like suicide & 50 & 2013 & $30-60$ & $83.72 \%$ & \\
\hline
\end{tabular}


communicable diseases such as CHD by the year 2025 [19].

\section{Discussion}

\section{From pathogenesis towards the} clinical manifestations of CAD

With the onset of atherosclerosis, the process of coronary artery narrowing begins with the presence of major risk factors (smoking, hyperlipidemia, diabetes mellitus, hypertension, obesity or metabolic syndrome, physical inactivity, and a family history of premature IHD, i.e. onset in a father, brother, or son before age 55 years or a mother, sister, or daughter before age 65 years) precipitate the coronary artery cross-sectional area narrowing. Even in the presence of these risk factors, we continued to see the nonlinear trend of growth in coronary stenosis for several years to decades. However, even in patients with non-obstructive CHD (stenosis $\geq 20 \%$ but $<70 \%$ ), it can still have a worse prognosis compare subjects with normal coronaries [20]. Therefore, secondary prevention in this non-obstructive CHD is very important to prevent AMI [21].

\section{- Patients with Stable Ischemic Heart Disease (SIHD)}

Patients with significant coronary obstructive disease, which is anatomically defined as left main coronary stenosis $>50.0 \%$ and/or coronary stenosis $>70.0 \%$, and is physiologically defined as FFR $<0.80$ (most recent studies used 0.80 rather than 0.75 as cut-off for lesion selection by FFR) [22], are divided into two groups. The first groups are those who are asymptomatic, which is a significant number and commonly found in the screening tests, and the second group of patients who are symptomatic TABLE 2. Noteworthy, according to the BART study, thirty percent of these patients with angina pectoris, despite different treatments, can't return to their past jobs [23].

In the United States, more than 17 million people suffer from CHD and more than 10 million Americans have a history of angina pectoris [1,24]. In half of the patients who analog with AMI, recently and in their history, they had unstable angina similar to angina but often more severe TABLE 3 [25].

For every thirty people with SIHD, one person per year is hospitalized with AMI (angina more severe and often lasting longer than $30 \mathrm{~min}$ which is almost always unrelieved by nitroglycerin). Therefore, treatment intervention, medically versus revascularization, following the diagnosis algorithm is promising [26-28]. Considering the pathophysiological events that occur in the heart following ischemia; ischemic cascade, the use of diagnostic methods in CHD can be understood and accepted FIGURES 1-3.

Although, each of the diagnostic tests presented in FIGURE 2 and TABLE4 have different diagnostic sensitivity, specificity, and disadvantage, that, in addition to help diagnoses of CHD, is also helpful for risk stratification. On the other hand, it should be taken into account that the sensitivity of each of the tests in the diagnosis of disease is different in men and women [29-38].

\section{Therapeutic strategies for coronary heart disease}

The goal of treatment is namely: a) maximize survival, b) preventing complications such

TABLE 2. Typical clinical features of major causes of acute chest discomfort.

\begin{tabular}{|l|l|}
\hline $\begin{array}{l}\text { Type of chest } \\
\text { pain }\end{array}$ & Clinical characteristics \\
\hline $\begin{array}{c}\text { Typical angina } \\
\text { (definite) }\end{array}$ & $\begin{array}{l}\text { 1. Substernal chest discomfort (heaviness, pressure, or squeezing), more than } 10 \text { seconds and less than } 10 \text { min that is } \\
\text { retrosternal, often with radiation to, or isolated discomfort in, neck, jaw, shoulders, or arms-frequently on the left. } \\
\text { 2. Provoked by exertion or emotional stress and } \\
\text { 3. Relieved by rest or nitroglycerine }\end{array}$ \\
\hline $\begin{array}{l}\text { Atypical } \\
\text { angina }\end{array}$ & Meets 2 of the above characteristics \\
\hline $\begin{array}{l}\text { Non-cardiac } \\
\text { chest pain }\end{array}$ & Meets 1 or none of the typical anginal characteristics \\
\hline
\end{tabular}

TABLE 3. Typical clinical features of unstable angina [25].

\begin{tabular}{|l|l|}
\hline Type of chest pain & Clinical Characteristics \\
\hline Rest angina & Angina occurring at rest and usually prolonged (20 min), occurring within 1 week of presentation \\
\hline New-onset angina & $\begin{array}{l}\text { Angina of at least Canadian Cardiovascular Society (CCS) Class III severity with onset within } 2 \text { months of initial } \\
\text { presentation }\end{array}$ \\
\hline Crescendo angina & Similar to angina, but often more severe and occurs with low levels of exertion or even at rest, or Post-MI angina \\
\hline
\end{tabular}



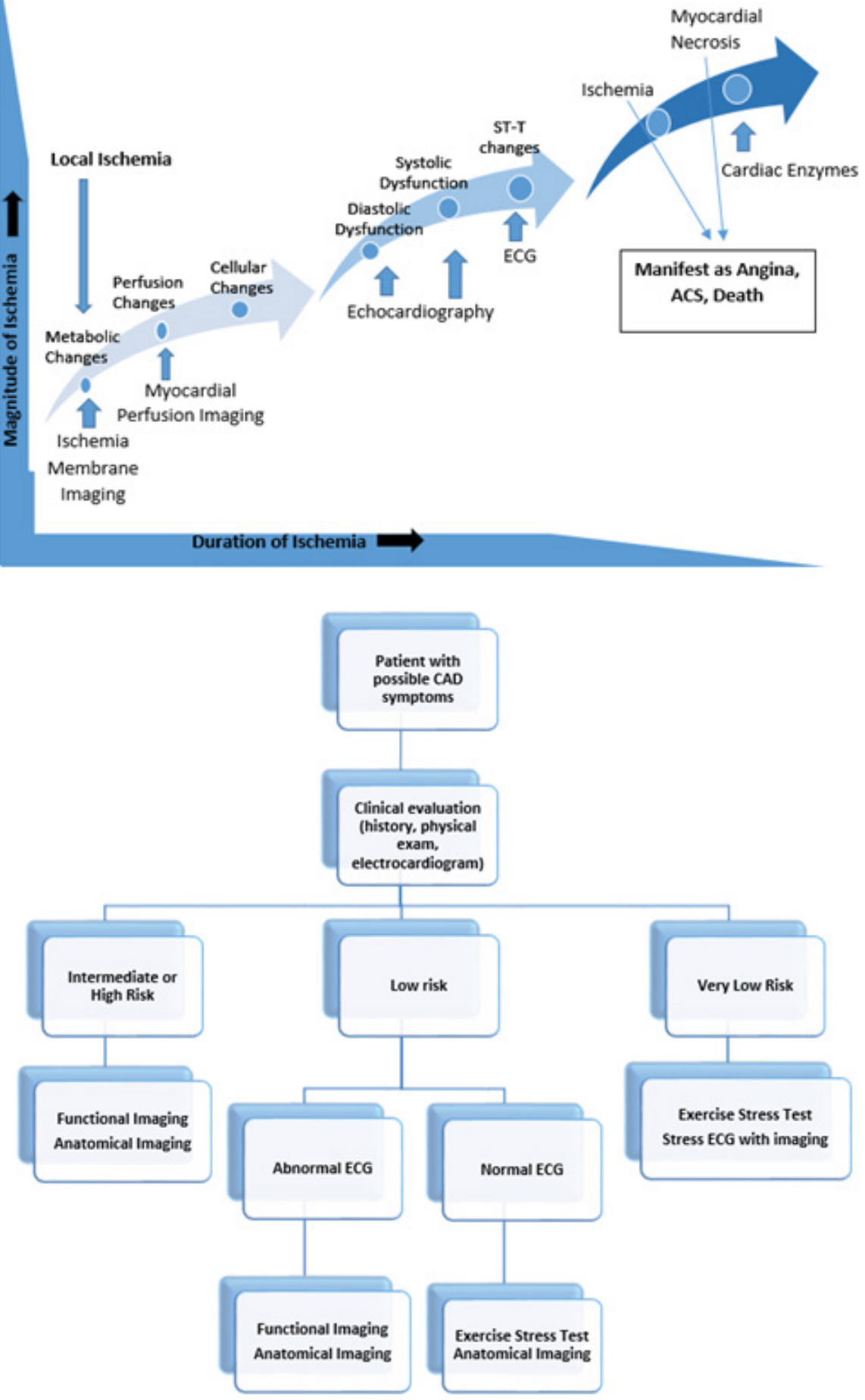

FIGURE 1. Ischemia cascade.

FIGURE 2. Non-invasive test selection algorithm for CHD diagnosis.

as myocardial infarction and heart failure, c) improving the quality of life in the patient's satisfaction, d) eliminating all or almost all ischemic symptoms and, ultimately, e) reducing the cost of treatment, including by reducing the frequency of hospitalizations. Noteworthy, in a study between 1980 and 2000 of over 341, 754 patients between the ages of 25 and 84 years, it was shown that mortality rates have been almost halved due to risk factor modification (primary prevention) and also, near half related to secondary prevention in post MI and post revascularization patients [39].

\section{Therapeutic strategies for patients} with stable ischemic heart disease

\section{Medical therapy}

Based on the result of Coronary Artery 
FIGURE 3. Algorithm 1, conduct to choose the PCI vs. CABG as a revascularization method.

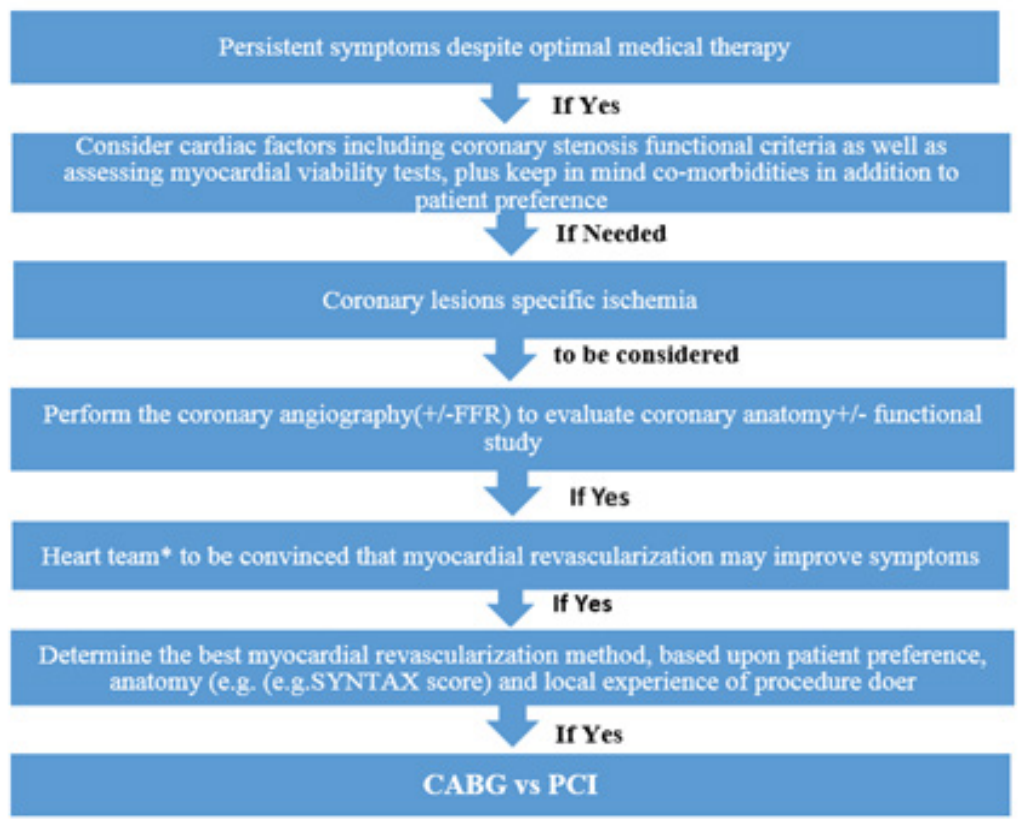

\begin{tabular}{|c|c|c|c|}
\hline Test & Disadvantages & Sensitivities and Specificities & Suitable test for \\
\hline $\begin{array}{l}\text { Electrocardiogram exercise } \\
\text { testing }\end{array}$ & $\begin{array}{l}8 / 100,000 \text { Cardiac complication } \\
\text { rate }\end{array}$ & $\begin{array}{l}\text { Sensitivities between } 45-50 \% \text { and } \\
\text { specificities of } 85-90 \%{ }^{*}\end{array}$ & $\begin{array}{l}\text { Exercise ECG is recommended as the initial } \\
\text { test for establishing diagnosis of CAD in } \\
\text { symptomatic patients with intermediate } \\
\text { PTP }\end{array}$ \\
\hline $\begin{array}{l}\text { Dobutamine Stress } \\
\text { Echocardiography }\end{array}$ & 42 VT/VF in 64542 cases; & $\begin{array}{l}\text { Sensitivities between } 80-85 \% \text { and } \\
\text { specificities of } 84-86 \%\end{array}$ & $\begin{array}{l}\text { Patients who are unable to do ETT, have } \\
\text { LBBB, or pacemaker }\end{array}$ \\
\hline \begin{tabular}{|l|} 
SPECT-MPI (Single Photon \\
Emission Computed \\
Tomography-Myocardial \\
Perfusion Image) \\
\end{tabular} & $\begin{array}{l}\text { Irradiation, } \\
\text { can miss } 3 \text { vessel disease } \\
\text { because of "balanced ischemia" }\end{array}$ & $\begin{array}{l}\text { Sensitivities between } 85-90 \% \text { and } \\
\text { specificities of } 70-75 \%^{*}\end{array}$ & $\begin{array}{l}\text { Patients who are unable to do ETT or do } \\
\text { inconclusive ETT, } \\
\text { have LBBB, pacemaker }\end{array}$ \\
\hline $\begin{array}{l}\text { CCTA (Coronary Computed } \\
\text { Tomography Angiography) }\end{array}$ & $\begin{array}{l}\text { Irradiation and contrast } \\
\text { toxicity, expensive, unavailable } \\
\text { worldwide }\end{array}$ & $\begin{array}{l}\text { Sensitivity of } 83.0 \% \text { and } \\
\text { specificity of } 81.6 \%{ }^{*}\end{array}$ & $\begin{array}{l}\text { Low to intermediate PTP (pretest } \\
\text { probability) }\end{array}$ \\
\hline \multirow{3}{*}{\begin{tabular}{|l|} 
Three- \\
dimensional Computed \\
tomography derived \\
fractional flow reserve (CT- \\
FFR) a novel noninvasive \\
method, was approved by \\
FDA in late 2014
\end{tabular}} & \multirow{2}{*}{$\begin{array}{l}\text { Irradiation and contrast } \\
\text { toxicity, expensive, unavailable } \\
\text { worldwide; }\end{array}$} & \multirow[t]{2}{*}{$\begin{array}{l}\text { Sensitivity of } 90.0 \% \text { and } \\
\text { specificity of } 82.0 \%{ }^{* *}\end{array}$} & $\begin{array}{l}\text { Assessment of correlation between } \\
\text { anatomical and functional significance of } \\
\text { coronary lesions, overcome to the severe } \\
\text { coronary artery calcification which is able } \\
\text { to cause blooming artifacts, }\end{array}$ \\
\hline & & & $\begin{array}{l}\text { CT-FFR guided strategy resulted in the } \\
\text { cancelation of } 61.0 \% \text { of the planned } \\
\text { coronary angiogram; saved a } 30.0 \% \text { of } \\
\text { medical cost to identify patients }\end{array}$ \\
\hline & $\begin{array}{l}\text { Currently, clinical trial data with } \\
\text { CT-FFR are insufficient to make } \\
\text { a recommendation for its use in } \\
\text { clinical practice [107]. }\end{array}$ & & \\
\hline \multirow[t]{2}{*}{$\begin{array}{l}\text { Stress Magnetic Resonance } \\
\text { Imaging }\end{array}$} & $\begin{array}{l}\text { NSF (nephrogenic systemic } \\
\text { fibrosis), costlier than many } \\
\text { other noninvasive tests, }\end{array}$ & \multirow[t]{2}{*}{$\begin{array}{l}\text { More a part of multimodality } \\
\text { tests for evaluation of impact on } \\
\text { the clinical care of CHD patients }\end{array}$} & \\
\hline & Not readily available & & \\
\hline Coronary Angiography & $\begin{array}{l}\text { Invasive procedure with } 1 / 1000 \\
\text { mortality rate, irradiation and } \\
\text { contrast toxicity, }\end{array}$ & $\begin{array}{l}\text { Anatomical information could } \\
\text { be misleading, needs further } \\
\text { functional assessment of lesion } \\
\text { severity (i.e. fractional flow } \\
\text { reserve) }\end{array}$ & $\begin{array}{l}\text { In whom revascularization is expected to } \\
\text { improve functional status or quality of life }\end{array}$ \\
\hline
\end{tabular}


Surgery Study (CASS) registry of medically treated patients, (23,467 patients' enrollment), overall, 12-year survival for patients with zero, one-, two- and three-vessel disease is $88 \%$, $74 \%, 59 \%$, and 40\%, respectively. Twelve-year survival for patients with at least one diseased vessel and ejection fractions in the ranges of $50 \%$ to $100 \%, 35 \%$ to $49 \%$ and $0 \%$ to $34 \%$ is $73 \%, 54 \%$ and $21 \%$, respectively [40]. After using different diagnostic methods and determining the risk, we divide the patients into two groups based on the possibility of annual cardiac mortality rate:

Group one: low risk SIHD patients (mortality rate of $<1.0 \%$ per year) to intermediate-risk SIHD patients (mortality rate of $1.0 \%-3.0 \%$ per year). For this group, change of lifestyle plus risk factors modification in addition to optimal medical therapy, because the effect of these drugs on symptoms improvement and increase in SIHD patient's longevity has been proven TABLE 5 [41-47].

Medical therapy starts with aspirin and follows the sequence that follows: sublingual nitroglycerin, beta-blockers (BBs), calcium channel blockers (CCBs) (when $\mathrm{BB}$ is contraindicated), long-acting nitrates, lipidlowering drugs and, finally, ranolazine. Betablockers are typically recommended as first-line treatment because of evidence that they reduce the risk of mortality post-MI and in those with hypertension.

Group two: high risk SIHD patients (mortality rate of $>3.0 \%$ per year). Treatment in this group comprises intensive medical therapy and revascularization, including percutaneous coronary intervention (PCI) versus coronary artery bypass surgery (CABG).

\section{Rationale for myocardial revascularization}

In cardiac patients who have not responded to optimal tolerable medical therapy, we consider TABLE 6 [48] for indication of revascularization and follow algorithm 1 to improve symptoms through myocardial revascularization.

In cardiac patients who have not responded to optimal tolerable medical therapy, we consider TABLE 7 to improve symptoms through myocardfiafl revascuflarfizatfion.

\section{- Percutaneous coronary intervention}

As a general principle, the less invasive method of treatment has priority between the two options. Therefore, because PCI is relatively non-invasive compared to CABG, we use the first option for the treatment of a medically unresponsive patient (medically responded patients is a term used for patients that could return to their ordinary life by using drugs with no cardiac symptoms).

\section{TABLE 5. Medical therapy for SIHD; effect on symptoms and/or mortality [41-47].}

\begin{tabular}{|l|l|}
\hline Drugs & Advantages \\
\hline $\begin{array}{l}\text { Antiplatelets including aspirin/ } \\
\text { clopidogrel [68] }\end{array}$ & $33 \%$ reduction in nonfatal MI or vascular death. \\
\hline Statins (Lipid-lowering drugs ) [69] & $24 \%$ reduction in nonfatal MI or coronary death, \\
\hline Beta blockers & $50 \%$ reduction in the frequency of angina attacks, \\
\cline { 2 - 2 } & $\begin{array}{l}\text { reduction in mortality in post Ml patients only if the drug is started during the first 24 hours post MI and } \\
\text { lasts for three years }\end{array}$ \\
\hline Calcium Channel Blockers & $50 \%$ reduction in the frequency of angina attacks \\
\hline Long acting nitrates & Improve exercise tolerance \\
\hline $\begin{array}{l}\text { Ranolazine (an inward sodium } \\
\text { channel inhibitor) }\end{array}$ & $22 \%$ reduction in recurrent ischemia \\
\hline $\begin{array}{l}\text { ACE inhibitors (Angiotensin- } \\
\text { Converting Enzyme Inhibitors) }\end{array}$ & $\begin{array}{l}\text { In all patients with SIHD who also have hypertension, diabetes mellitus, LVEF 40\% or less, or CKD, unless } \\
\text { contraindicated; (reduction in cardiovascular death between 22.0\%-37\%) }\end{array}$ \\
\hline Annual Influenza Vaccine & annual influenza vaccinations reduced the risk of mortality by 37\% during the winter period \\
\hline
\end{tabular}

TABLE 6. Indications for revascularization in patients with stable angina or silent ischemia [48].

\begin{tabular}{|l|l|l|l|}
\hline Extent of CAD (anatomical and/or functional) & Class of Recommendation & Level of Evidence \\
\hline For Prognosis & Left main disease with stenosis $>50 \%$ & $\mathrm{I}$ & $\mathrm{A}$ \\
\hline & Proximal LAD stenosis $>50 \%$ & $\mathrm{I}$ & $\mathrm{A}$ \\
\hline & 2VD or 3VD with $>50 \%$ stenosis+LVEF $<35.0 \%$ & $\mathrm{~A}$ \\
\hline & $\begin{array}{l}\text { Large size of ischemia detected by functional testing i.e. }>10.0 \% \text { or } \\
\text { abnormal invasive FFR }\end{array}$ & $\mathrm{I}$ & $\mathrm{B}$ \\
\hline & Single remaining patent coronary artery $>50.0 \%$ stenosis & $\mathrm{C}$ \\
\hline For Symptoms & $\begin{array}{l}\text { Hemodynamically significant CAD in the presence of limiting angina or } \\
\text { angina equivalent with insufficient response to optimal medical therapy }\end{array}$ & $\mathrm{I}$ & $\mathrm{A}$ \\
\hline
\end{tabular}


Moreover, the main point here is that the purpose of using these two methods is to first determine which group of revascularization procedures (PCI vs. CABG) has been able to reduce mortality. On the other hand, are there previous studies sufficiently indicative of the reduction of possible short and long-term potential cardiovascular risks to CHD patients who have been subjected to such invasive procedures?

Anatomical complexity of CAD (SYNTAX score; Synergy between Percutaneous Coronary Intervention with Taxus and Cardiac Surgery, summarized in TABLE 8 and FIGURES 4 and 5, to grade the anatomical complexity of coronary lesions in patients with left main or three-vessel disease), predicted surgical mortality (EUROSCORE; European System for Cardiac Operative Risk Evaluation, and the STS score; the Society of Thoracic Surgeons score) and the anticipated completeness of revascularization are further important criteria for decision-making to choose PCI versus CABG approach.

The most important goal of PCI is to reduce the pain and cardiac ischemic symptoms, reduce the frequency of repetitive hospitalization and eliminate ischemia. Several Randomized
Clinical Trials (RCT) have shown that the PCI procedure does not reduce the number of deaths and myocardial infarction [49,5059]. Moreover, evaluation of 61 trials of PCI those have done during past three decades shows that despite improvements in PCI technology and pharmacotherapy, PCI has not been demonstrated to reduce the risk of death or MI in patients without recent ACS [60]. In the COURAGE trial (Clinical Outcomes Utilizing Revascularization and Aggressive Drug Evaluation), which had published in 2015 in the New England Journal of Medicine, there were no survival rate differences in the follow-up of 15 years in 2,287 patients who were divided into two groups of drug treatment and PCI [61].

Therefore, the patient should be aware that the general belief that PCI will reduce the chance of heart attacks and cardiac death after PCI is wrong. On the other hand, long-term use of Dual Antiplatelet Therapy (DAPT) after PCI is costly and accompanied with possible complications. The patient's knowledge of the information that has been mentioned would help the patient to cleverly choose his own therapeutic method, a point that is very important, but unfortunately, is usually ignored

TABLE 7. Myocardial Revascularization to improve symptoms in CAD patients unresponsive to optimal medical therapy or who do not have enough compliance to get medical therapy [50].

\begin{tabular}{|c|c|c|c|}
\hline Clinical Setting & Method & $\begin{array}{l}\text { AHA/ACC Class of } \\
\text { Recommendation }\end{array}$ & $\begin{array}{l}\text { Level of } \\
\text { Evidence }\end{array}$ \\
\hline $\begin{array}{l}\text { Lack of anatomic/functional criteria for Myocardial } \\
\text { Revascularization }\end{array}$ & $\mathrm{CABG}$ or $\mathrm{PCl}$ & III & C \\
\hline $\begin{array}{l}\text { One or more significant stenosis feasible for } \\
\text { Myocardial Revascularization }\end{array}$ & CABG or $\mathrm{PCl}$ & I & A \\
\hline \multirow[t]{2}{*}{ Previous CABG with one or more significant stenosis } & $\mathrm{PCl}$ & Ila & C \\
\hline & CABG & Ila & B \\
\hline $\begin{array}{l}\text { Complex three vessel disease with or without } \\
\text { proximal LAD involvement and a good candidate } \\
\text { for CABG }\end{array}$ & CABG preferred over $\mathrm{PCl}$ & Ila & B \\
\hline $\begin{array}{l}\text { Multi-sites ischemia perfused by unfeasible vessels } \\
\text { for CABG }\end{array}$ & $\begin{array}{l}\text { Transmyocardial Revascularization as } \\
\text { an ancillary procedure to CABG }\end{array}$ & Illb & B \\
\hline
\end{tabular}

TABLE 8. SYNTAX Scoring (11 measures of lesion complexity).

\section{Guides for SYNTAX Scoring}

Step 1.

Step 2.

Dominance (LCx or RCA)

Step 3. Coronary segment

Step 4.

Diameter stenosis

Step 5.

Trifurcation lesion

Step 6.

Bifurcation lesion

Step 7.

Step 8.

Step 9.

Step10.

Aort-ostial lesion

Severe tortuosity

Lesion length

Step11. Calcification Thrombus

Diffuse disease/small vessels 


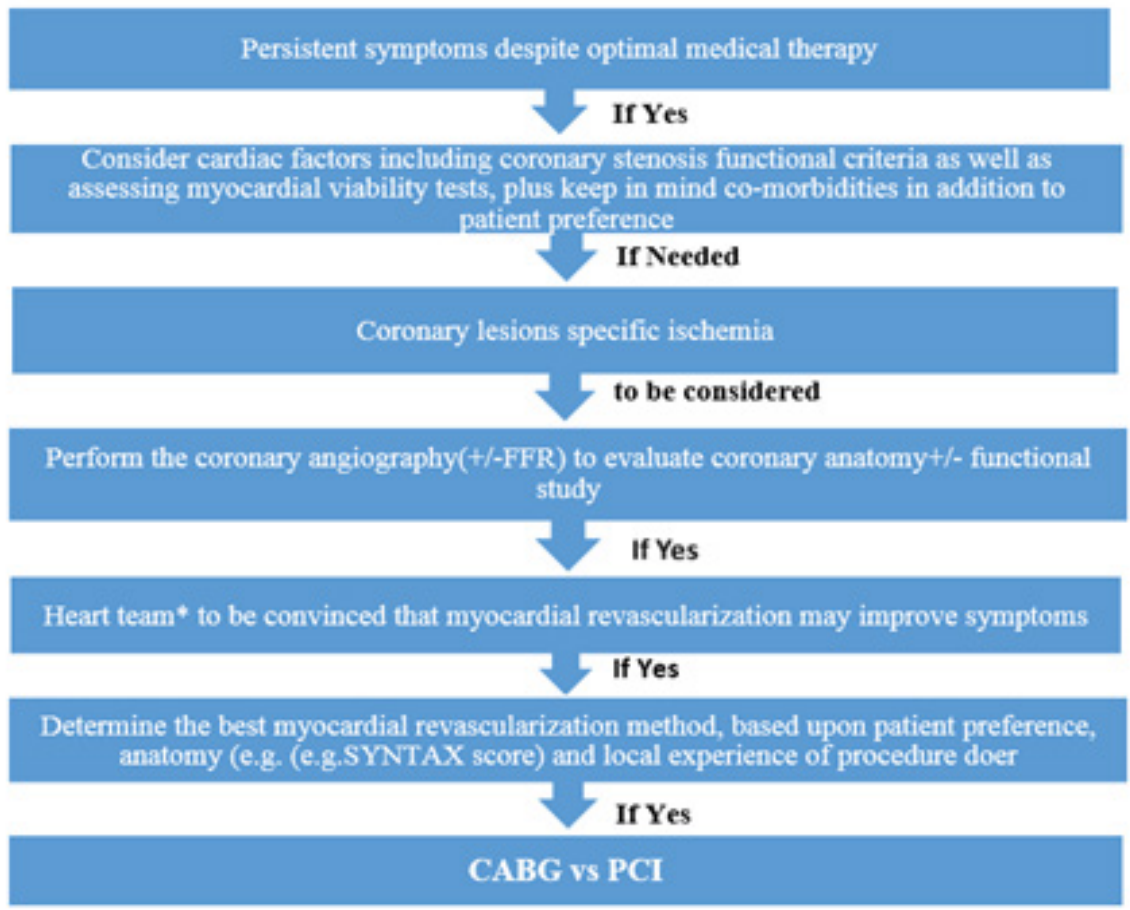

FIGURE 4. Definition of the coronary tree segments.

\section{Left dominance}
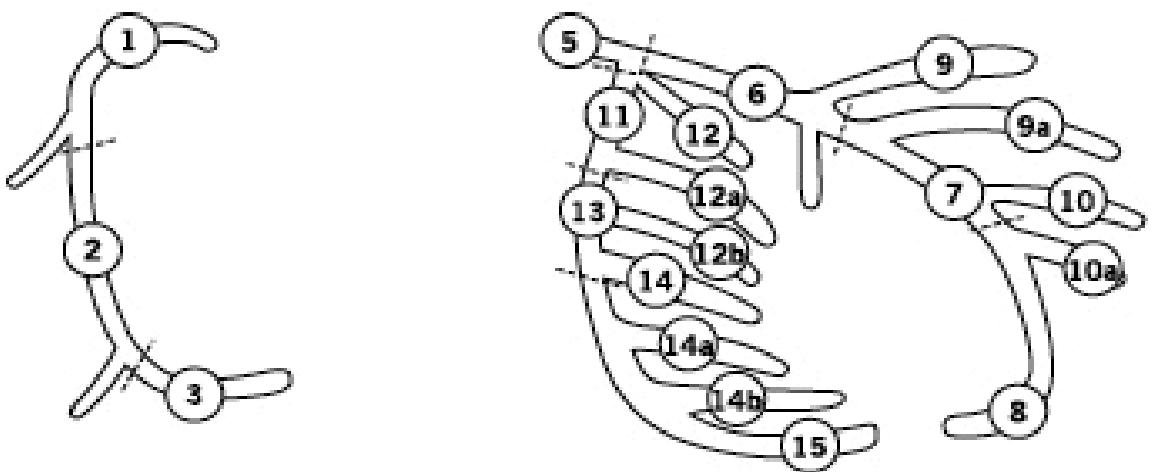

Right dominance

FIGURE 5. Total occlusion length segment.

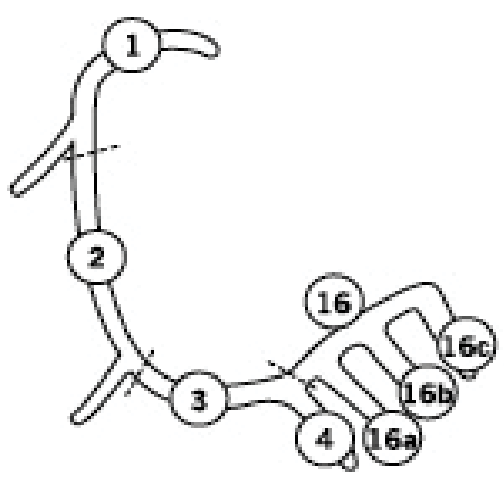

$[24,62,63]$. However, newer everolimus drugeluting stents have better survival rate than older ones [64], especially if the patient is FFR-guided chosen for doing PCI [65].

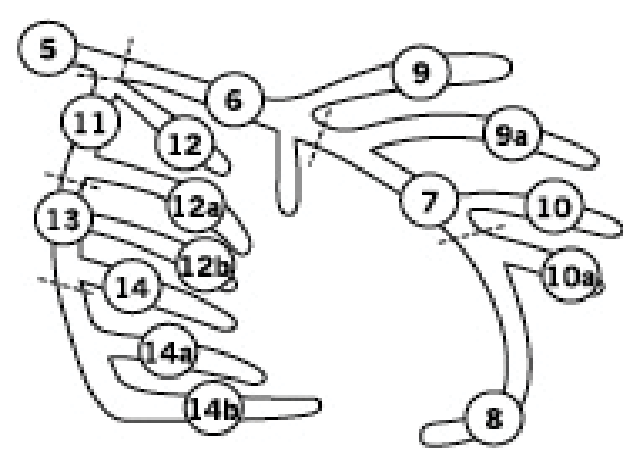


22; intermediate, 23 to 32 and 33: high. Based on the SYNTAX trial results that were published in 2009 in New England Journal of Medicine, at one year follow up, CABG had lower rates of the Major Cardiac And Cerebrovascular Events (MACCE) compared to PCI for patients with three-vessel or left main CAD. The occurrence of MACCE correlated with the SYNTAX score for DES patients but not for those undergoing CABG. At one-year follow-up, the primary endpoint was similar for CABG and DES in those with a low SYNTAX score. In contrast, MACCE occurred more often after DES implantation than after CABG in those with an intermediate or high SYNTAX score [66]. At 3 years of follow-up, the mortality rate was greater in subjects with 3-vessel CAD treated with PCI than in those treated with CABG $(6.2 \%$ vs. $2.9 \%)$.

Because SYNTAX trial was considered to anatomical conditions, further, and in several studies, other parameters that have a clinical aspect such as age, gender, presence of COPD, LVEF status, keratinize clearance and peripheral vascular disease have interfered in the process of investigation in order to determine the selection outcome of the preferred procedure (PCI vs. CABG) [67].

\section{Coronary artery bypass graft surgery}

Noteworthy, in a study by Pittman MA et al., it has shown that CABG is only associated with a decrease in mortality in a group with left main coronary disease [68]. Although, in the past it was thought that patients with a SIHD and left ventricular systolic dysfunction would have a lower mortality rate with CABG, in the STICH trial (Surgical Treatment for Ischemic Heart Failure), initially and during a five-year period follow up, it was shown that the reduction in CABG patients' deaths differ very little compared to those who received medical therapy alone and did not have CABG (28.0\% death due to cardiovascular cause in CABG group compared to $33.0 \%$ mortality in group who had been on medical therapy) [69]. However, the extended 10-year follow-up of the STICH trial reported a significant reduction in all-cause mortality rate $(59 \%$ vs. $66 \%$ respectively) [70]. Also, in the MASS II study (Medicine, Angioplasty, or Surgery Study II); in the group undergoing $\mathrm{CABG}$, there was a lower incidence of myocardial infarction, frequent revascularization, and cardiac death during the ten-year follow-up period, in comparison to patients who received medical therapy [71].
On the other hand, in comparison between CABG and PCI with Drug-Eluting Stent (DES) in a meta-analysis of 24, 268 patients with multi-vessel CAD, it was found that there is no difference between the rate of myocardial infarction and mortality between both groups, but the frequency of repeat revascularization was four times higher after DES implantation [72].

The note that should be addressed is patients with left ventricular systolic dysfunction that can be due to hibernation or stunning, and performing myocardial revascularization would help to improve the function of the left ventricle, as long as the process of checking the muscle's vitality is determined and approved by performing tests such as dobutamine stress echocardiography, late gadolinium enhancement cardiac magnetic resonance or PET scan (Class IIb recommendation with level of evidence B) [73-76]. However, the meta-analysis from published series examining late survival with revascularization versus medical therapy after myocardial viability testing in patients with severe Coronary Artery Disease (CAD) and Left Ventricular (LV) dysfunction demonstrates a strong association between myocardial viability on noninvasive testing and improved survival after revascularization in patients with chronic $\mathrm{CAD}$ and LV dysfunction. Absence of viability was associated with no significant difference in outcomes, irrespective of treatment strategy [74].

It should also be pointed out that if coronary stenosis adjusted myocardial ischemia/viability approved by the tests have described, it is not necessary to carry out FFR guided decision making for doing myocardial revascularization in patients with stenosis of intermediate stenosis [48].

What is important in choosing the method of PCI versus CABG selection is the prediction of residual SYNTAX score, which we get at the end of the procedure, i.e. when more than the number 8 for residual score, would be with negative consequences and poor prognosis (associated with significant increases in the 5-year risk of death and of the composite of death, MI, and stroke) [77]. The aim of choosing each type revascularization is to reduce the risk of death and MI by reducing residual stress-induced ischemia from $>10 \%$ of the myocardium to $\leq 5 \%$ [78]. Also, calculation of in hospital 30 days' mortality for patients who are candidates for CABG by using STS (Society of Thoracic Surgeons) scoring is another important thing 
that should be considered (ESC Guideline class I level of evidence B) [76].

It is easy to make decisions for the heart team in a summary that is summarized in TABLE 9.

For diabetic patients with advanced CAD, based on the FREEDOM trial results (Future Revascularization Evaluation in Patients with Diabetes Mellitus: Optimal Management of Multivessel Disease), CABG was superior to PCI, i.e. significantly reduced rates of death and myocardial infarction, with a higher rate of stroke of 5 years' duration with a minimum of 3 years of follow-up [79].

On the other hand, if we incorporate results of SYNTAX score and FREEDOM Trial, CABG should be offered as the first-line therapy in patients which mentioned in TABLE 10 for myocardial revascularization.

\section{- Therapeutic strategies for patients with acute coronary syndrome/ Non-ST elevation myocardial infarction (ACS)/ NSTE)}

In surveys of patients referred to the hospital with chest pain, it has been shown that $50 \%$ of them are non-cardiac pain, $35 \%$ are ACS and ultimately $15 \%$ are other cardiac conditions. The acute coronary syndrome is commonly associated with three clinical manifestations: ST-elevation myocardial infarction (STEMI, $10 \%)$, non-ST elevation myocardial infarction
(NSTEMI, 15\%), or unstable angina (10\%) [80].

The main initiating mechanism in ACS is a rupture of the coronary atherosclerotic plaque with superimposed thrombus formation. Vascular endothelial response to inflammatory and mitogenic substances that were released from activated platelets in addition to coronary spasm may cause ACS FIGURE 6.

In case of suspicion of unstable angina, if the patient has no ongoing ischemic symptoms, normal ECGs in addition to normal results of two/three serial (hs) cTn tests, the patient is not required to stay in hospital and could perform a non-invasive stress test in outpatient follow up, preferably with imaging because of superiority to exercise ECG testing.

For patients with a high degree of clinical suspicion of NSTEMI, coronary angiography and for patients with low to intermediate likelihood, CCTA should be considered [80].

If the hospital test results were positive, the ECG changes were in favor of ischemia/ infarction and/or regional wall motion abnormality was noted on echocardiography, even with negative biomarkers and normal ECGs, the patient should remain in the hospital. During the hospital course, the patient needs heart monitoring, continuing anti-ischemic therapy including oxygen therapy if saturation

\begin{tabular}{|c|c|}
\hline PCI would be first choice & CABG would be the first choice \\
\hline Anatomical criteria & Anatomical criteria \\
\hline Multi-vessel disease with SYNTAX score $=0-22$ & Multi-vessel disease with SYNTAX score $\geq 23$ \\
\hline $\begin{array}{l}\text { Possibility of incomplete revascularization with CABG is } \\
\text { high }\end{array}$ & Possibility of incomplete revascularization with $\mathrm{PCl}$ is high \\
\hline Chest wall or spine deformity & $\begin{array}{l}\text { Severely calcified coronaries that possibility of stent under-expansion would be } \\
\text { high }\end{array}$ \\
\hline \multicolumn{2}{|l|}{ Chet radiotherapy in past with sequelae } \\
\hline \multicolumn{2}{|l|}{ Porcelain aorta } \\
\hline Clinical criteria & Clinical criteria \\
\hline Presence of severe co-morbidity & Diabetes \\
\hline Advanced age & LVEF $<35.0 \%$ \\
\hline \multirow[t]{2}{*}{ Restricted post op rehabilitation would be predicted } & DAPT would be contraindicated \\
\hline & Recurrent in-stent restenosis \\
\hline
\end{tabular}

TABLE 10. Incorporation of SYNTAX score and FREEDOM trial.

CABG should be offered as the first line for myocardial revascularization:

\begin{tabular}{|l|l|}
\hline $\mathbf{1}$ & 3VD and SYNTAX score $>32$ \\
\hline $\mathbf{2}$ & 3VD with proximal LAD involvement and SYNTAX score $>22$ \\
\hline $\mathbf{3}$ & 3VD in a diabetic patient \\
\hline $\mathbf{4}$ & 2VD in a diabetic patient with proximal LAD involvement and SYNTAX \\
\cline { 2 - 2 } & score $>22$ \\
\hline $\mathbf{5}$ & Unprotected left main (ULM) disease with SYNTAX score $>32$ \\
\hline
\end{tabular}


FIGURE 6. Classification of acute coronary syndromes based on ECG and cardiac isoenzymes. "Cardiac biomarker; preferably high-sensitivity cardiac troponin; (hs)cTn, couple blood samples taking at admission and three hours later (+/- another sample six hours later) [111].

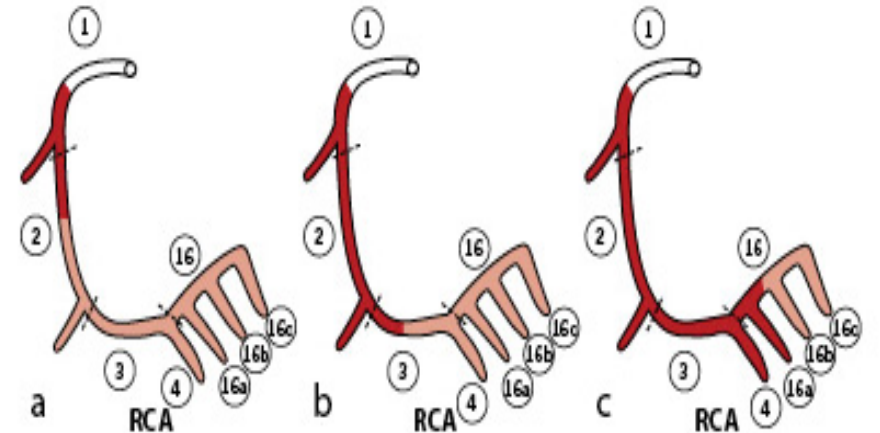

Patent segment

Occluded segment

Segment distal from the occlusion filled with collateral flow (visualised by contrast)

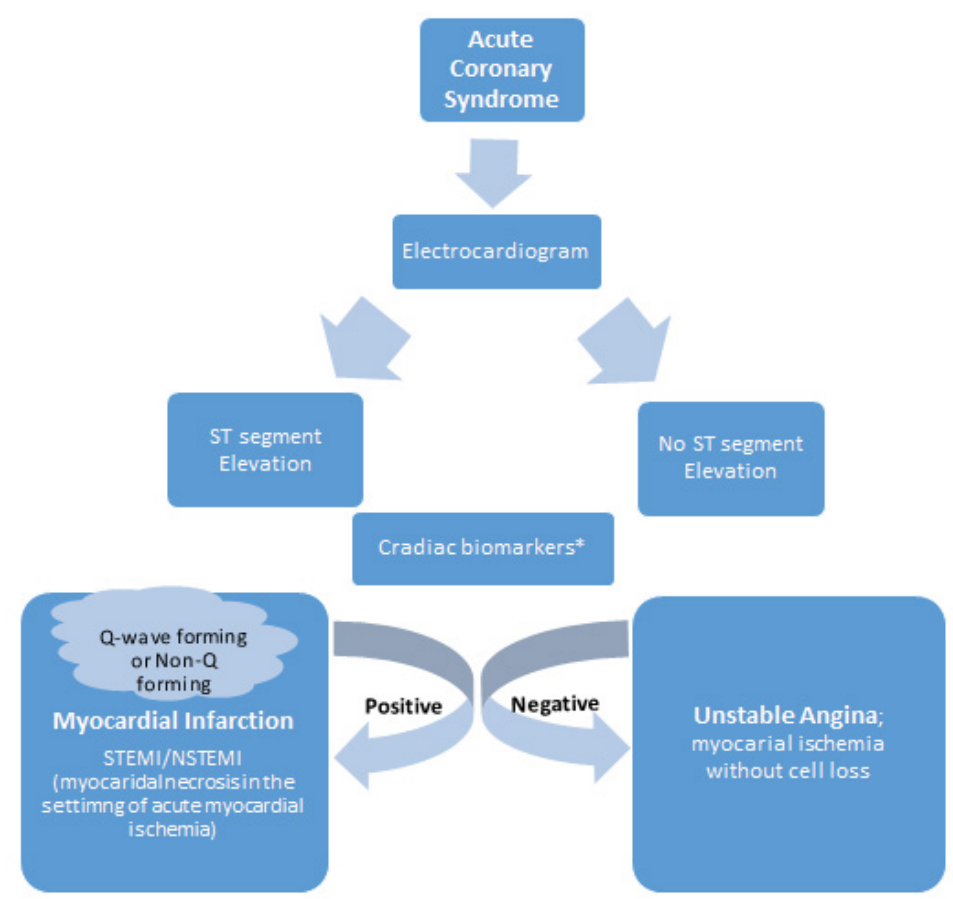

is less than 90\%. Also drug therapy namely intravenous nitrate, Dual Antiplatelet Therapy (DAPT) comprising plain aspirin and a P2Y12 inhibitor (prasugrel or ticagrelor preferred over clopidogrel) in combination with anticoagulants; LMWH (fondaparinux is recommended as having the most favorable efficacy-safety profile regardless of the management strategy) $[81,82]$ or UFH, early administration of beta-blocker (BB), and calcium channel blocker instead of $\mathrm{BB}$ if coronary spasm is most likely cause should be continued and considering immediate diagnostic coronary angiography [80].

From a certain point of view, the main advantages of PCI compared to CABG in the setting of NSTE-ACS are faster revascularization of the culprit lesion, a lower risk of stroke and the absence of deleterious effects of cardiopulmonary bypass on the ischemic myocardium. However, from another view, CABG may more frequently offer complete revascularization in advanced multivessel CAD.

Overall, in patients considered at very high or high risks of ischemic events, especially in biomarker positive cases, invasive therapeutic strategy including stenting of the culprit lesion in addition to antiplatelet and GPIIb / IIIa inhibitor would lower mortality rate and 
ischemic recurrences. Although this strategy is accompanied with higher peri-procedural complication, it would cause a shorter duration of hospital stay rather than medical therapy (as it has been shown in at least seven RCTs) [83]

\section{FIGURE 7.}

While in patients with SIHD, the functional assessment of coronary stenosis severity by using FFR is considered, so far, the value of FFRguided PCI in NSTEMI has not been properly addressed (because maximal hyperemia in NSTEMI patients would not be achieved) [84].

A Danish nationwide cohort study has shown that from 2001 to 2009, the proportion of NSTEMI patients undergoing coronary angiography and PCI markedly increased, causing only $10 \%$ of NSTEMI patients undergoing coronary angiography scheduled for $\mathrm{CABG}$ and expecting higher mortality/ morbidity (like bleeding) in comparison with elective CABGs [85]. Notably, aspirin as well as a P2Y12 inhibitor is recommended and should be maintained over 12 months for post NSTEMI patients undergone CABG as well (class I indication, level of evidence A) [86,87].

Although NSTEMI patients who are not amenable for revascularization (due to severe/ diffuse CAD) are sparse, intensification of antiischemic therapy would be the best therapeutic modality, albeit, with the prediction of poorer response and higher mortality.

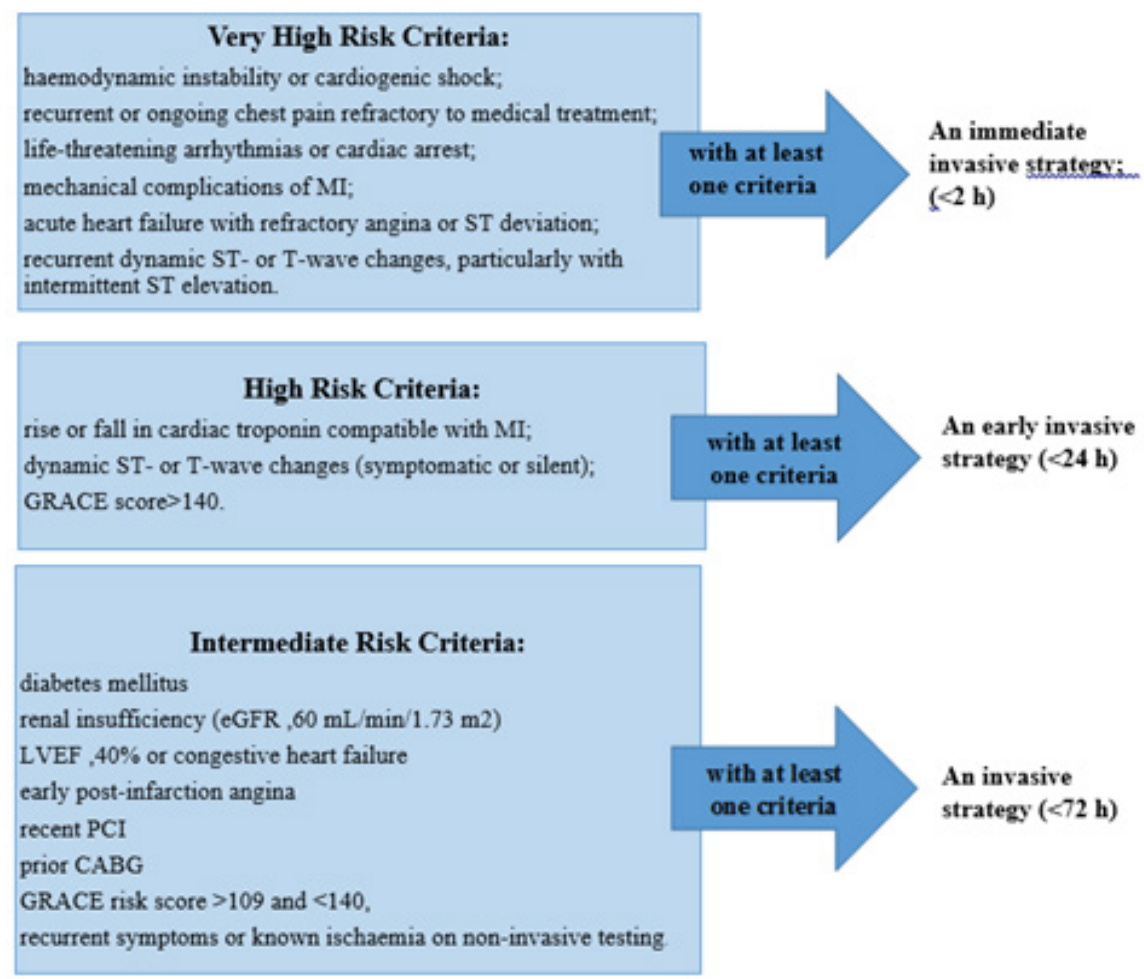

Decisions to perform staged PCI or planned CABG for non-culprit lesions in the presence of the multivessel disease may be determined at a later date. Recommendations for PCI and CABG in stabilized NSTE-ACS are similar to those for stable CAD.

Noteworthy, approximately $25 \%$ of NSTEMI patients have myocardial infarction in the absence of obstructive coronary artery disease (MINOCA), management of these patients are medically like patients with SIHD, surely excluding oral nitrates [88]. CMR is indicated within 2 weeks after the onset of symptoms to increase the diagnostic accuracy of the test for identifying the etiological cause of MINOCA [89].

\section{Therapeutic strategies for patients with ST segment elevation MI (STEMI)}

Definition of acute myocardial infarction is based on the evidence of clinical ischemia in addition to biomarker stigmata in favor of myocardial necrosis; the best biomarker test in high sensitivity cardiac troponin with at least one value above the $99^{\text {th }}$ percentile upper reference limit [90]. The majority of STEMI patients classified as type 1 MI (coronary thrombus related) and a minority of them as type 2 (MINOCA). Because the immediate reperfusion therapy should be considered in patients with STEMI, therefore, carefully and
FIGURE 7. Suggested policy for choosing appropriate time of invasive strategy in NSTE-ACS patients; Based on 2015 ECG guidelines. 
obsessively, ECG should be assessed for STsegment elevation to diagnose promptly. To define STEMI, it needs to be in at least two contiguous leads with ST-segment elevation in leads V2-V3, $2.5 \mathrm{~mm}$ in men $<40$ years, $2 \mathrm{~mm}$ in men 40 years, or $1.5 \mathrm{~mm}$ in women and/or in the other leads $1 \mathrm{~mm}$ [90]. Leads V3R and V4R for right ventricular MI and leads V7-V9 ST elevation during the first 6 hours could be helpful.

\section{- Pre-hospital care}

In the context of a possible diagnosis of myocardial infarction, prevention of delay for further steps is very crucial. "Count every minute" is a short but important message that has a long history regarding treatment of STEMI patient to minimize pre and in-hospital delays.

One of the most important points is to delay between the onset of pain and contact with the Emergency Medical Service (EMS). Of course, it is very important to raise public awareness regarding the symptoms of myocardial infarction so they can quickly inform the EMS.

The initial visit of the EMS staff to the first ECG should preferably take less than ten minutes. Also, the EMS staff should be highly skilled for ECG interpretation to allow for rapid diagnosis of STEMI, have fully trained in advanced life support and be able to undertake defibrillation if needed. To shorten time to treatment, fibrinolysis should be administered in the pre-hospital setting if possible [91].

\section{- In-hospital care}

Quickly transferring the STEMI patient to hospitals with an established PPCI programmer available 24/7 and bypassing the emergency department to bring the patient directly to the well-equipped catheterization lab, surely minimizes the pre-hospital delay and have impressive positive impact on prognosis. Optimal acceptable delay (pre and in-hospital) for interrogation regarding STEMI patients is summarized in algorithm 3 FIGURE 8.

\section{Some important points that should be considered in STEMI patients classified with class I indications}

1. Transradial access is superior to trans femoral access by an experienced operator [92]

2. Stenting is recommended (over balloon angioplasty) for primary PCI [93]
3. Stenting with new-generation DES (such as everolimus or biolimus-eluting stents) is recommended over BMS for primary PCI [94,95]

Some important points that should be considered in STEMI patients classified with class Ila indications

1. Routine revascularization of non-IRA lesions should be considered in STEMI patients with the multivessel disease before hospital discharge $[96,97]$

2. Non-IRA PCI during the index procedure should be considered in patients with cardiogenic shock

\section{Some important points that should} be considered in STEMI patients classified with class III indications

1. Routine use of thrombus aspiration is not recommended $[98,99]$

2. Routine use of deferred stenting is not recommended [100,101]

\section{Some important points that are noteworthy to know}

1. In terms of the same time delay to choose a method, primary PCI strategy is superior to fibrinolysis in reducing mortality, reinfarction, or stroke, However, when primary PCI is not an immediate option, fibrinolysis should be initiated promptly [102-105]

2. Based on DANAMI 3-DEFER trial and in 1, 215 STEMI patients that deferred stenting to reduce microvascular obstruction (MVO) and preserve microcirculatory function $(48 \mathrm{~h}$ after the index procedure) no positive impact on the primary clinical outcome was shown [106]

3. Although elderly patients are at particularly higher risks, there is no upper age limit with respect to reperfusion, especially with primary PCI; based on TRIANA trial results [107]

4. In various published studies, the beneficial effect of the intra-aortic balloon counterpulsation during primary PCI for anterior wall STEMI without cardiogenic shock had not shown on infarct size reducing [108] and even no improvement in outcomes in AMI patients with cardiogenic shock [109] 


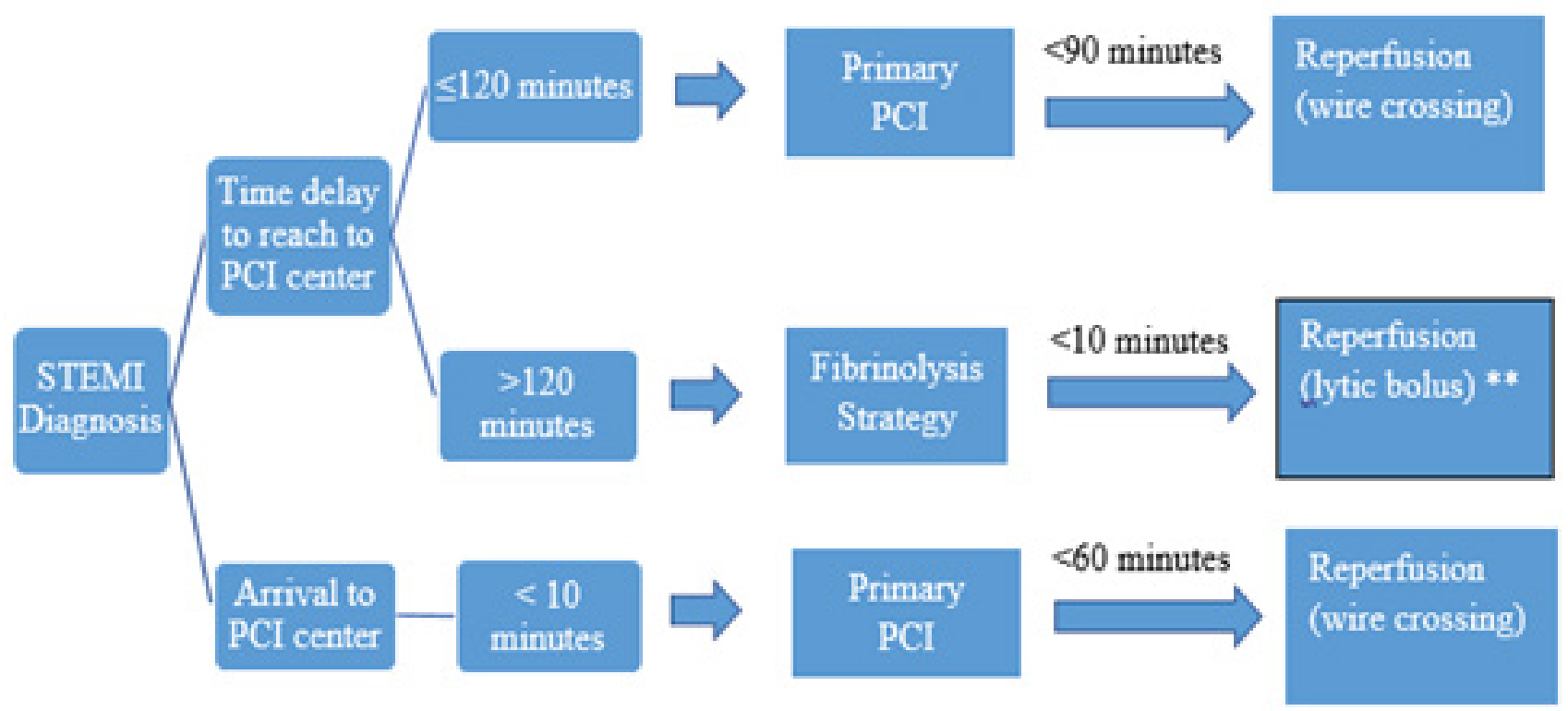

FIGURE 8. Algorithm 3-Optimal acceptable delay for interrogation regarding STEMI patients. *Definition of Primary $\mathrm{PCI}(\mathrm{PPCl}$ ) strategy is emergent coronary angiography and $\mathrm{PCl}$ of infracted related atery (IRA) if needed.

${ }^{* *}$ Patients with fibrinolysis should be transferred to a PCl centre immediately after administration of the lytic bolus for performing rescue PCI strategy (indicated in the case of failed fibrinolysis, i.e. ST-segment resolution $<50 \%$ within $60-90$ min of fibrinolytic administration, in the presence of haemodynamic or electrical instability, worsening ischemia, or persistent chest pain, maximum expected delay <one hour) or pharmacoinvasive strategy (coronary angiography and PCI of IRA if needed between 2 and 24 hours after successful fibrinolysis).

5. In the absence of ST-segment elevation, a primary PCI strategy is indicated in patients with suspected ongoing ischaemic symptoms suggestive of MI and at least one of the following criteria present:

- hemodynamic instability or cardiogenic shock

- recurrent or ongoing chest pain refractory to medical treatment

- life-threatening arrhythmias or cardiac arrest

- mechanical complications of MI

- acute heart failure

- Recurrent dynamic ST-segment or wave changes, particularly with intermittent ST-segment elevation

1. In the situation with time delay $>12 \mathrm{hrs,}$ a primary PCI strategy is still indicated in the presence of ongoing symptoms suggestive of ischemia, hemodynamic instability, or life-threatening arrhythmias [110]

2. Coronary angiography is justified within 24 hrs. if STEMI patient becomes ischemic symptoms-free, in addition, to complete restoration of elevated ST- segment to baseline or after nitroglycerine administration

3. Patients with ST-elevation on postresuscitation ECG should undergo a primary PCI strategy (class I indication, Level of evidence B)

4. Elevated levels of cTn measurements in patients with heart failure, either HFpEF or HFrEF, may be seen, therefore, always raising the level of the cTn test does not mean an AMI, and its interpretation should be accompanied by other clinical signs with ECG ischemic evidence, and even after some more workups such as angiography, to make sure that myocardial infarction happened

5. Takotsubo syndrome (TTS): can mimic MI and is found in $1 \%-2 \%$ of patients presenting with suspected STEMI, however, this syndrome is a myocardial injury and not categorized as MI

- TTS is secondary to the high catecholamine surges that are known to trigger cTn release from cardiomyocytes and causing modest elevation of cTn, nevertheless, the clinical manifestations and ECG abnormalities are out of proportion to the degree of elevation 
of cTn values. However, coronary angiography (in most cases is normal) and ventriculography are often needed to secure the diagnosis

- Although the inpatient mortality is similar to STEMI (4\%-5\%) due to cardiogenic shock, ventricular rupture, or malignant arrhythmias, meanwhile, almost always the long term outcome is excellent, because the systolic function usually returns to normal during hours to weeks. The distinction between MI and TTS can be challenging, particularly when concurrent CAD is present. CMR is very helpful in this context, especially in the absence of recovery of regional wall motion abnormalities, LGE-CMR is recommended to exclude MI with spontaneous recanalization. Two additional features that are helpful in distinguishing TTS from acute MI are QTc prolongation $>500 \mathrm{~ms}$ during the acute phase and the recovery of LV function over 2-4 weeks [111-113]

1. MINOCA: The prevalence of MINOCA is estimated to be $6 \%-8 \%$ among patients diagnosed with $\mathrm{MI}$ and more common in women than men, as well as in patients presenting with NSTEMI compared with those presenting with STEMI. Atherosclerotic plaque disruption and coronary thrombosis may be a cause of MINOCA, i.e. type 1 MI. However, coronary spasm and spontaneous coronary dissection may be involved as well, i.e. type $2 \mathrm{MI}$, along with other possible causes [114]

2. Contrary to chronic heart failure, natriuretic peptides are of limited value for the diagnosis of acute heart failure following MI due to the lack of definite cut-off values for diagnosis in these patients [115]

3. It should be emphasized that despite greater use of reperfusion therapy, primary percutaneous coronary intervention (PPCI), modern antithrombotic therapy, and secondary prevention, the hospital and one-year mortality among the STEMI patients are still substantial and had been reported as $12.0 \%$ and $10.0 \%$ respectively $[116,117]$

\section{- Atypical electrocardiographic presentations in patients with ongoing myocardial ischemia symptoms}

In the clinical context with ongoing chest pain, not uncommonly, ECGs are inconclusive. For example, patients with LBBB, RBBB, pacemaker or graft vein occlusion.

\section{LBBB pattern or Pacemaker rhythm}

For diagnosis of $\mathrm{MI}$ in the presence of LBBB, different algorithms have been offered in various reports but no one has enough certainty so far. Although in this context, concordant ST elevation in leads with positive QRS might be very helpful for STEMI diagnosis, overall it is logical to consider these with clinical evidence of ongoing ischemia and LBBB to be the same as STEMI patients [118]. We do have the same dilemma regarding pacemaker dependent patients [119].

\section{RBBB pattern}

In the other side, because the diagnosis of trans mural ischemia as well as STEMI in the presence of $\mathrm{RBBB}$ is usually difficult, therefore, for these patients, the primary PCI policy like for the other STEMI patients should be considered [120].

\section{Vein grafts left circumflex artery acute occlusion}

In daily practice, cardiologists are not uncommon facing to cases of acute coronary occlusion with no ST elevation, such as graft vein or left circumflex artery occlusion, so fibrinolytic therapy is denied. Thus, it is reasonable to do primary PCI strategy in any suspicious patient suffering from ongoing myocardial ischemia $[121,122]$.

\section{Left main coronary obstruction}

In patients who presented with chest pain and one millimeter or more ST depression in $\geq 8$ surface leads (inferolateral ST depression), in addition to ST-segment elevation in aVR and/or V1, suggests multivessel ischemia or left main coronary artery obstruction, particularly if the patient presents with haemodynamic compromise and, therefore, needs primary PCI strategy [123].

\section{Old age, CKD and DM patients}

Owing to the ageing of the population, a higher proportion of elderly patients is expected 
to present with STEMI. The prevalence of diabetes mellitus and/or kidney dysfunction in patients with myocardial infarction is higher than in the general population, and both are associated with a higher incidence of infarction related complications as well as mortality. Although several antithrombotic agents should either be withheld or their doses reduced in CKD patients, selection of antithrombotics and reperfusion therapy is the same as in patients without diabetes. The blood glucose level goal in STEMI patients would be $<200 \mathrm{mg} / \mathrm{Dl}$. In the other side of view, hypoglycemia is very harmful in this context.

\section{Post MI cardiac arrest}

In patients following out of hospital cardiac arrest and ST-segment elevation on the ECG, primary PCI is the strategy of choice. Given the high prevalence of coronary occlusions and the potential difficulties in interpreting the ECG in patients after cardiac arrest, urgent angiography (within 2 hrs.) should be considered in survivors of cardiac arrest, including unresponsive survivors, when there is a high index of suspicion of ongoing infarction (such as the presence of chest pain before arrest, a history of established $\mathrm{CAD}$, and abnormal or uncertain ECG results). Given the high prevalence of coronary occlusions and the potential difficulties in interpreting the ECG in patients after cardiac arrest, urgent angiography (within $2 \mathrm{hrs}$ ) should be considered in survivors of cardiac arrest, including unresponsive survivors, when there is a high index of suspicion of ongoing infarction (such as the presence of chest pain before arrest, a history of established CAD, and abnormal or uncertain ECG results).

Also, it should be reemphasized that in cases without ST-segment elevation on postresuscitation ECG but with a high suspicion of ongoing myocardial ischemia, urgent angiography should be done within 2 hrs. after a quick evaluation to exclude noncoronary causes. In all cases, the decision to perform urgent coronary angiography should take into account factors associated with poor neurological outcome.

Targeted temperature management is indicated early after resuscitation of cardiac arrest patients who remain unresponsive (class I indication, Level of evidence B). Targeted temperature management refers to active methods (i.e. cooling catheters, cooling blankets, and application of ice applied around the body) to achieve and maintain a constant specific body temperature between $32^{\circ} \mathrm{C}$ and $36^{\circ} \mathrm{C}$ in a person for a specific duration of time (most commonly used 24 h) [124]. Keep in mind, that cooling like opioids have a negative impact on gastrointestinal clopidogrel absorption.

\section{Periprocedural and post- procedural antithrombotic therapy in patients undergoing primary percutaneous coronary intervention}

Patients undergoing primary PCI should receive DAPT, a combination of aspirin and a P2Y12 inhibitor, and a parenteral anticoagulant.

\section{Antiplatelets}

Aspirin: Aspirin (non-enteric-coated formulation) should preferably be $150-300 \mathrm{mg}$. The superiority of single dose of 250 or $500 \mathrm{mg}$ acetylsalicylic acid intravenously compare to oral chewable $300 \mathrm{mg}$ aspirin has been shown, based on a recent published RCT [125].

\section{P2Y12 inhibitors}

1. Prasugrel: [ $60 \mathrm{mg}$ loading dose and $10 \mathrm{mg}$ maintenance dose once daily (p.o.)]

2. Ticagrelor: (180 mg p.o. loading dose and $90 \mathrm{mg}$ maintenance dose twice daily)

3. Both of the above drugs have a more rapid onset of action, greater potency, and are superior to clopidogrel in clinical outcomes, however, neither should be used in patients with a previous haemorrhagic stroke, in patients on oral anticoagulants, or in patients with moderate-to-severe liver disease [126,127].

4. Clopidogrel: when neither of the above drugs is available (or if they are contraindicated), clopidogrel should be given instead (600 mg p.o. loading dose and $150 \mathrm{mg}$ maintenance dose daily) [128],

- Notably, opioids, as well as hypothermia which are used for unconscious patients, have a negative impact on clopidogrel absorption

- Early treatment with high-dose clopidogrel was superior to incatheterization laboratory treatment in observational studies and one small randomized trial [129-131]

5. Cangrelor: is an i.v. Adenosine Triphosphate (ATP) analog that binds 
reversibly and with high affinity to the platelet P2Y12 receptor and has a short plasma half-life $(10 \mathrm{~min})$. It may be considered in patients not pre-treated with oral P2Y12 receptor inhibitors at the time of PCI or in those who are considered unable to absorb oral agents $[88,132]$.

\section{GP IIb/IIla inhibitors}

Abciximab, eptifibatide (integrin), tirofiban: All are not recommended for routine use in the setting of primary PCI. In few circumstances and for special cases like post-procedure thrombus burden stent or when no-reflow phenomenon happened, these drugs might be used. Nonetheless, intracoronary administration of GP IIb/IIIa inhibitors is not superior to its use [133].

\section{Anticoagulants}

1. Ultra Fractionated Heparin (UFH), initial i.e. bolus 70-100 U/kg: While there is a long-term experience with UHF in PPCI, there is no published placebo-controlled trial in this context so far

2. Enoxaparin, i.e. bolus of enoxaparin 0.5 $\mathrm{mg} / \mathrm{kg}$. In a meta-analysis of 23 PCI trials (30 966 patients, 33\% primary $\mathrm{PCI}$ ), an i.e. bolus of enoxaparin $0.5 \mathrm{mg} / \mathrm{kg}$ was associated with a significant reduction in death compared to UHF; this effect was particularly significant in the primary PCI context and was associated with a reduction in major bleeding (class II an indication with level of evidence A) [134]

3. Bivalirudin i.e. bolus $0.75 \mathrm{mg} / \mathrm{kg}$ followed by infusion of $1.75 \mathrm{mg} / \mathrm{kg} /$ hour for up to 4 hours after the procedure: A metaanalysis of five RCT trials showed no mortality advantage with bivalirudin and a reduction in the risk of major bleeding, but at the cost of an increased risk of acute stent thrombosis [135], however, for patients with heparininduced thrombocytopenia, bivalirudin is recommended as the anticoagulant agent during primary $\mathrm{PCI}$

4. Fondaparinux is not recommended for primary PCI, based on the result of the OASIS 6 trial; Organization for the Assessment of Strategies for Ischemic Syndromes 6 (class III indication) [136]

In the presence of separate indication for fulldose anticoagulation, such as left ventricular clot, post-procedural anticoagulation therapy would be indicated; otherwise, it should be stopped to minimize peri-procedural bleeding risk.

However, approximately $6 \%-8 \%$ of patients undergoing PCI have an indication for longterm Oral Anticoagulation Therapy (OAC) with Vitamin K Antagonist (VKA) or Novel Oral Anticoagulants (NOACs) due to various conditions. In this context, for most post PPCI patients, triple therapy in the form of aspirin, clopidogrel and oral anticoagulation, (albeit with a target international normalized ratio in the lower part of the recommended target range for VKA and the lowest effective tested dose for NOAC), should be considered for 6 months. Then, oral anticoagulation plus aspirin or clopidogrel should be considered for an additional 6 months, the latter is superior to the former. After 1 year, it is indicated to maintain only oral anticoagulation.

\section{Fibrinolytic therapy}

Fibrinolytic therapy prevents 30 deaths per 1000 patients treated within $6 \mathrm{~h}$ after symptom onset [137].

For patients who had been on oral anticoagulation since before, fibrinolysis is a relative contraindication. DAPT should be added to OAC to prepare the STEMI patients for PPCI. GP IIb/IIIa inhibitors, prasugrel, and ticagrelor should be avoided.

\section{All of the below statements are regarding fibrinolytic therapy and classified as class I indication (ESC Guideline 2017)}

1. When fibrinolysis is the reperfusion strategy, it is recommended to initiate this treatment as soon as possible after STEMI diagnosis, preferably in the pre-hospital setting $[138,139]$

2. A fibrin-specific agent (tenecteplase, alteplase or reteplase) is recommended and is superior to streptokinase [140]

- $\quad$ Alteplase (tPA): $15 \mathrm{mg}$ i.e. bolus, 0.75 $\mathrm{mg} / \mathrm{kg}$ i.e. over $30 \mathrm{~min}$, then $0.5 \mathrm{mg} / \mathrm{kg}$ i.e. over $60 \mathrm{~min}$

- Reteplase (rPA): 10 units+10 units i.e. bolus given $30 \mathrm{~min}$ apart

- $\quad$ Tenecteplase (TNK-tPA): $30 \mathrm{mg}$ for $<60$ $\mathrm{kg}, 35 \mathrm{mg}$ for $<70 \mathrm{~kg}, 40 \mathrm{mg}$ for $<80 \mathrm{~kg}$, $45 \mathrm{mg}$ for $<90 \mathrm{~kg}$, and $50 \mathrm{mg}$ for $\geq 90 \mathrm{~kg}$ 
3. Streptokinase: 1.5 million units over 30 60 min i.e

4. Clopidogrel is indicated in addition to aspirin [140]

5. Anticoagulation is recommended in patients treated with a fibrin-specific agent until revascularization (if performed) or for the duration of hospital stay up to 8 days with

- enoxaparin i.e. followed by s.c. preferred over UFH [141]

- regarding streptokinase, the scenario is different

- Significantly fewer reinfarctions were seen with bivalirudin given for $48 \mathrm{~h}$ compared with UFH [142]

6. Transfer to a PCI-capable center following fibrinolysis is indicated in all patients immediately after fibrinolysis (pharmacoinvasive strategy) [143] and, of course, a shorter time from symptom onset to angiography (<4hours) would be appreciated, however, a time window of 2-24 h after successful lysis is recommended [144]

7. When fibrinolysis has failed, rescue PCI is indicated immediately; in this setting, fibrinolysis re-administration has not been shown to be beneficial and should be discouraged [145]

8. Emergency angiography and PCI if indicated is recommended in patients with heart failure/shock [146]

9. Prolonged, or traumatic but successful, resuscitation increases bleeding risk and is a relative contraindication to fibrinolysis; otherwise, short successful resuscitation would not be contraindicated

\section{- CABG as a therapeutic modality in the setting of STEMI should be considered in the below situations}

1. For patients with a patent IRA but with unsuitable anatomy for PCI, emergent CABG is needed

2. For patients with a patent IRA and a large myocardial with cardiogenic shock [147]

3. For patients with a patent IRA and a large myocardial area at jeopardy

4. For patients with MI-related mechanical complications who require coronary revascularization

5. In patients with failed PCI or coronary occlusion not amenable to PCI, emergent CABG in this setting is uncertain

6. In stabilized post-MI patients, optimal timing for no emergent $\mathrm{CABG}$ is uncertain

7. No difference is present between STEMI and NSTEMI patients who underwent PPCI and on DAPT; if the patient is hemodynamically unstable with recurrent ischemic episodes, emergent CABG is needed, despite the presence of antiplatelet effects due to DAPT usage

8. DAPT usage up to one-year post CABG has class I indication

\section{Post-hospital care}

\section{Lifestyle interventions}

1. Quit smoking $(36 \%$ reduction of mortality in quitters)

2. Optimal blood pressure control; systolic blood pressure (SBP) target of $<140$ $\mathrm{mmHg}$

3. Diet advice (a diet similar to the Mediterranean diet)

4. Weight control

5. Exercise-based cardiac rehabilitation; all AMI patients should participate in an exercise-based cardiac, rehabilitation program with expected $22 \%$ reduction in cardiac mortality rate [148]

Drug therapy (all the below drugs are classified as class I indication in STEMI patients)

1. Beta-blockers in past, had recommended in all MI patients to reduce long term mortality, however, it should be considered in STEMI patients only as discussed in detail in the heart failure guidelines (in patients with LVEF $\leq 40 \%$, in the absence of contraindications such as acute heart failure, hemodynamic instability, or higher degree AV block) [149]

2. Statins with intensive therapy method are recommended in all patients with AMI, irrespective of cholesterol concentration at presentation, with the treatment goal of an LDL-C concentration of $<70 \mathrm{mg} / \mathrm{dL}$

3. Ezetimibe is an alternative for statins in 
patients who are statin intolerants and as co-adjuvant in patients who not responded properly to intensive statin alone

4. Nitrates are not recommended as routine use in STEMI, based on the non-beneficial results in a randomized controlled trial against placebo [89], however, following the acute phase, nitrates remain valuable agents to control residual angina symptoms

5. Calcium channel blockers are only indicated in STEMI patients with contraindications to beta-blockers, albeit in patients without heart failure or impaired LV function

6. Angiotensin Converting Enzyme (ACE) inhibitors is recommended in all STEMI patients with $\mathrm{LVEF} \leq 40 \%$, hypertension, or diabetes

7. Angiotensin Ii Receptor Blockers (ARBs) are recommended in STEMI patients who need ACE inhibitors but can't tolerate it

8. Mineralocorticoid Receptor Antagonist (MRA) therapy is recommended in patients with LVEF $\leq 40 \%$ and heart failure after STEMI

9. Aspirin (75-100 mg) is recommended indefinitely in all patients with STEMI that have shown in a meta-analysis of RCTs [150]

10. P2Y12 inhibitor in addition to aspirin (DAPT) is not only recommended in patients with STEMI who are undergoing primary PCI (for up to 12 months), but also in patients treated with fibrinolysis without subsequent PCI [151]; Clopidogrel is the P2Y12 inhibitor of choice as co-adjuvant and after fibrinolysis, because of results of two major studies, there are no

\section{TABLE 11. Clinical classification of myocardial infarction (from fourth universal definition of myocardial infarction, 2018).}

\section{Type of Myocardial Infarction Definition Criteria}

Type 1 MI: The term acute myocardial infarction should be used when there is acute myocardial injury with clinical evidence of acute myocardial ischemia and with detection of a rise and/or fall of cTn values with at least one value above the $99^{\text {th }}$ percentile URL and at least one of the following:

- Symptoms of myocardial ischemia;

- New ischemic ECG changes;

Criteria for acute myocardial - Development of pathological $Q$ waves; infarction (types 1, 2 and $3 \mathrm{MI}$ )

\begin{tabular}{|c|c|}
\hline & $\begin{array}{l}\text { - Imaging evidence of new loss of viable myocardium or new regional wall motion abnormality in a pattern } \\
\text { consistent with an ischemic etiology; }\end{array}$ \\
\hline & $\begin{array}{l}\text { - Identification of a coronary thrombus by angiography or autopsy (not for types } 2 \text { or } 3 \mathrm{MIs} \text { ), Post-mortem } \\
\text { demonstration of acute athero-thrombosis in the artery supplying the infarcted myocardium meets criteria } \\
\text { for type } 1 \mathrm{MI}\end{array}$ \\
\hline & $\begin{array}{l}\text { Type } 2 \text { MI: Evidence of an imbalance between myocardial oxygen supply and demand unrelated to acute } \\
\text { athero-thrombosis meets criteria for type } 2 \text { Ml. }\end{array}$ \\
\hline & $\begin{array}{l}\text { Type } 3 \text { MI: Cardiac death in patients with symptoms suggestive of myocardial ischemia and presumed new } \\
\text { ischemic ECG changes before cTn values become available or abnormal meets criteria for type } 3 \mathrm{MI} \text {. }\end{array}$ \\
\hline & $\begin{array}{l}\text { Type 4a,4b,4c and } 5 \text { MI: Percutaneous Coronary Intervention }(\mathrm{PCI}) \text { related } \mathrm{MI} \text { is termed type } 4 \mathrm{M} \mathrm{MI} \text {. } \\
\text { Coronary Artery Bypass Grafting (CABG) related } \mathrm{MI} \text { is termed type } 5 \mathrm{MI} \text {. Coronary procedure-related } \mathrm{MI} \leq \\
48 \text { hours after the index procedure is arbitrarily defined by an elevation of cTn values }>5 \text { times for type } 4 \mathrm{a} \\
\mathrm{MI} \text { and }>10 \text { times for type } 5 \mathrm{MI} \text { of the } 99 \text { th percentile URL in patients with normal baseline values. Patients } \\
\text { with elevated pre-procedural cTn values, in whom the pre-procedural cTn level are stable ( } \leq 20 \% \text { variation) } \\
\text { or falling, must meet the criteria for a }>5 \text { or }>10 \text {-fold increase and manifest a change from the baseline } \\
\text { value of }>20 \% \text {. In addition, with at least one of the following: }\end{array}$ \\
\hline & - New ischemic ECG changes (this criterion is related to type 4a MI only); \\
\hline $\begin{array}{l}\text { Criteria for coronary } \\
\text { procedure-related myocardial } \\
\text { infarction }\end{array}$ & - Development of new pathological Q waves \\
\hline \multirow[t]{3}{*}{ (types 4 and $5 \mathrm{MI}$ ) } & $\begin{array}{l}\text { - Imaging evidence of loss of viable myocardium that is presumed to be new and in a pattern consistent } \\
\text { with an ischemic etiology; }\end{array}$ \\
\hline & $\begin{array}{l}\text { - Angiographic findings consistent with a procedural flow-limiting complication such as coronary } \\
\text { dissection, occlusion of a major epicardial artery or graft, side-branch occlusion-thrombus, disruption of } \\
\text { collateral flow or distal embolization. Isolated development of new pathological Q waves meets the type 4a } \\
\text { MI or type } 5 \mathrm{MI} \text { criteria with either revascularization procedure if cTn values are elevated and rising but less } \\
\text { than the pre-specified thresholds for PCI and CABG. }\end{array}$ \\
\hline & $\begin{array}{l}\text { Other types of } 4 \mathrm{Ml} \text { include type } 4 \mathrm{~b} \mathrm{Ml} \text { stent thrombosis and type } 4 \mathrm{c} \mathrm{MI} \text { restenosis that both meet type } 1 \mathrm{MI} \\
\text { criteria. Post-mortem demonstration of a procedure-related thrombus meets the type } 4 \mathrm{a} \mathrm{Ml} \text { criteria or type } \\
4 \mathrm{~b} \mathrm{Ml} \text { criteria if associated with a stent. }\end{array}$ \\
\hline
\end{tabular}


formal recommendations for the use of clopidogrel or prasugrel beyond 1 year $[152,153]$

Oral anticoagulation in STEMI patients with stent implantation who need to receive it, then, triple therapy should be considered for 1-6 months.

\section{Device therapy}

ICD therapy is recommended to reduce sudden cardiac death in patients with symptomatic heart failure (New York Heart Association class II-III) and $\leq 35 \%$, despite optimal medical therapy for $>3$ months and at least 6 weeks after MI, who are expected to survive for at least 1 year with good functional status.

Lately, in 2018, a universal definition of myocardial infarction with updated concepts has categorized to five below types TABLE 11.

\section{Focused Update of the different guidelines for the use of antiplatelet therapy}

The important point that is quoted in the 2017 ESC Guidelines for the management of acute myocardial infarction in patients presenting with ST-segment elevation, which contains unanswered questions, should be insisted: "What is the best acute and maintenance antithrombotic regimen in patients who have an indication for oral anticoagulants? What is the best timing for the loading dose of oral P2Y12 inhibitors and what are the best strategies for i.e. antithrombotic therapies? What is the role of potent P2Y12 inhibitors in patients undergoing fibrinolysis? What is the real role of aspirin in this new era of potent antiplatelet agents and low dose anticoagulation? What is the best duration of maintenance therapy with P2Y12 inhibitors as single or multiple antithrombotic regimens?"

Although, maintenance therapy in the majority of patients is based on one-year DAPT in the form of aspirin plus prasugrel/ticagrelor, however, another unresolved issue that should be added to above-mentioned questions is the duration of using dual antiplatelet drugs in post PCI and/ or CABG, which is still debated. In selected patients with low bleeding risk and very high ischemic risk, extended DAPT $(>12$ months) could be considered [115]. Therefore, additional data is necessary to establish the optimal duration of dual antiplatelet therapy following stent implantation

Of course, another dilemma is the decision about the best time of discontinuing DAPT and/or anticoagulation in post $\mathrm{PCI}$ and/ or CABG patients who scheduled for non-cardiac operations.

Among the available and updated guidelines to conduct the use of DAPT, from our point of view, "2018 Update of the Canadian Cardiovascular Society Antiplatelet Guidelines" is more practical and feasible and. of course complete and reliable, so in this article, we recommend using it. Also, the recommendation provided in this guideline for heart patients on DAPT and/or OAC who need non-cardiac surgery is more applicable to the authors of this overview article TABLES 12-14 and FIGURES 9 and 10.

\section{8 update of the canadian cardiovascular society/canadian association of interventional cardiology antiplatelet guidelines [154]}

Management of patients with implanted coronary stents and/or CABG who on dual antiplatelet therapy and need to undergo noncardiac surgery

Based on 2016 ACC/AHA Guideline Focused

TABLE 12. Recommendations for duration of DAPT in patients with ACS (STEMI or NSTEACS) who undergo PCI.

Recommendations:

In patients with ACS (STEMI or NSTEMI) who receive $\mathrm{PCI}$ :

- We recommend DAPT with ASA $81 \mathrm{mg}$ daily with either ticagrelor $90 \mathrm{mg}$ BID or prasugrel $10 \mathrm{mg}$ once daily over clopidogrel $75 \mathrm{mg}$ once daily for 1 year (Strong Recommendation; High-Quality Evidence)

- We recommend that, in patients who tolerate 1 year of DAPT without a major bleeding event and who are not at high risk of bleeding, DAPT should be extended beyond 1 year (Strong Recommendation; High-Quality Evidence for up to 3 years of treatment)

- $\quad$ After 1 year, we recommend a DAPT regimen of ASA $81 \mathrm{mg}$ daily plus either ticagrelor $60 \mathrm{mg}$ BID or clopidogrel $75 \mathrm{mg}$ once daily (Strong Recommendation; High-Quality Evidence) or prasugrel $10 \mathrm{mg}$ once daily (Weak Recommendation; Moderate-Quality Evidence)

Values and preferences. These recommendations place greater emphasis on reduction of major CV events and stent thrombosis vs an increase in bleeding complications 


\section{TABLE 13. Recommendations for duration of DAPT in patients who undergo elective PCI.}

\section{Recommendations: \\ In patients undergoing $\mathrm{PCl}$ for a non-ACS indication (e.g., stable ischemic heart disease):}

- We recommend 6 months (and up to 1 year) of DAPT with ASA and clopidogrel (Strong Recommendation; Moderate-Quality Evidence)

- We suggest that in patients who have additional high risk clinical or angiographic features for thrombotic CV events and who are at low risk of bleeding, it is reasonable to extend the duration of DAPT to $>1$ year (Weak Recommendation; Moderate-Quality Evidence for up to 3 years of treatment)

- We suggest that in patients who are at high risk of bleeding, the duration of DAPT be shortened to a minimum of 1 month (if a bare-metal stent (BMS) is used) or 3 months (if a DES is used) (Weak Recommendation; Low-Quality Evidence)

Values and preferences These recommendations place greater emphasis on reduction of major CV thrombotic events and stent thrombosis v.s. an increase in bleeding complications. These recommendations presume that patients who experience a clinically significant bleed or at high risk of bleeding would be reassessed for the appropriateness of continuation of DAPT at 1 year.

TABLE 14. Recommendations for patients on DAPT who candidate for surgery.

\section{Recommendations:}

- In patients undergoing $\mathrm{PCl}$ who are treated with a BMS and who require elective noncardiac surgery, we recommend delaying surgery for at least 1 month after PCI (Strong Recommendation; Moderate-Quality Evidence)

- In patients undergoing $\mathrm{PCI}$ who are treated with a DES and who require elective noncardiac surgery, we recommend delaying surgery for at least 3 months after PCI (Strong Recommendation; Moderate-Quality Evidence). If there is a need for semi-urgent noncardiac surgery, we suggest delaying surgery for at least 1 month after PCI (Weak Recommendation; Low-Quality Evidence)

- In patients undergoing $\mathrm{PCI}$ who are treated with either a BMS or DES and who require elective noncardiac surgery, we suggest continuing ASA perioperatively whenever possible (Weak Recommendation; Low-Quality Evidence)

- In patients undergoing $\mathrm{PCI}$ who are treated with a BMS or DES and who require elective noncardiac surgery, we suggest withholding clopidogrel and ticagrelor for 5-7 days preoperatively, and prasugrel for 7-10 days preoperatively (Weak Recommendation; Low-Quality Evidence)

- In patients undergoing PCI who are treated with a BMS or DES and who have undergone noncardiac surgery, we suggest restarting maintenance-dose DAPT after surgery, as soon as it is deemed safe by the surgeon (Weak Recommendation; Very LowQuality Evidence)

- We recommend continuation of ASA in all patients with ACS who require CABG surgery (Strong Recommendation; ModerateQuality Evidence)

- To minimize the risk of bleeding, for patients with an ACS who are receiving ticagrelor and need semi-urgent CABG, we suggest a minimum interruption of ticagrelor for 48-72 hours before CABG (Weak Recommendation; Low-Quality Evidence) and recommend an ideal interruption period of 5 days before elective CABG (Strong Recommendation; Moderate-Quality Evidence)

- To minimize the risk of bleeding, for patients with an ACS who are receiving clopidogrel and need semi-urgent CABG, we suggest a minimum interruption of clopidogrel for 48-72 hours before CABG (Weak Recommendation; Low-Quality Evidence) and recommend an ideal interruption period of 5 days before elective CABG (Strong Recommendation; Moderate-Quality Evidence)

- To minimize the risk of bleeding, for patients with an ACS who are receiving prasugrel and need semi-urgent CABG, we suggest a minimum interruption of prasugrel for 5 days before CABG (Weak Recommendation; Very Low-Quality Evidence) and recommend an ideal interruption period of 7 days before elective CABG (Strong Recommendation; Moderate-Quality Evidence)

In patients with a previous valve replacement who undergo $\mathrm{PCI}$ for an ACS or non-ACS indication:

- $\quad$ For patients with a mechanical valve replacement, we suggest an initial regimen of ASA $81 \mathrm{mg}$ daily plus clopidogrel $75 \mathrm{mg}$ daily plus a VKA (triple therapy). ASA may be discontinued as early as the day after PCl or it can be continued up to 6 months of treatment, depending on the risk of recurrent thrombotic events vs major bleeding (Weak Recommendation; Very Low-Quality Evidence)

- $\quad$ For patients with a mechanical valve replacement, we recommend against the use of a NOAC regardless of whether it is in combination with antiplatelet therapy or used alone (Strong Recommendation; Moderate-Quality Evidence)

Update on Duration of Dual Antiplatelet Therapy in Patients with Coronary Artery Disease, regarding patients with an indication for oral anticoagulation in addition to DAPT, the below recommendation has introduced TABLE 15 [155]:

CHA2DS2-VASc indicates congestive heart failure, hypertension, age $\geq 75$ years (doubled), diabetes mellitus, prior stroke or transient ischemic attack or thromboembolism (doubled), vascular disease, age 65-74 years, sex category; HAS-BLED, hypertension, abnormal renal/liver function, stroke, bleeding history or predisposition, labile INR, elderly, drugs/alcohol concomitantly; INR, international normalized ratio; and PPIs, proton pump inhibitors.

Based on a 2017 ESC focused update on dual antiplatelet therapy in coronary artery disease developed in collaboration with EACTS, regarding patients with an indication for oral anticoagulation in addition to DAPT, the below recommendation were introduced TABLE 16.

Some important below key messages have notified by 2017 ESC focused update on DAPT that need to be considered: 

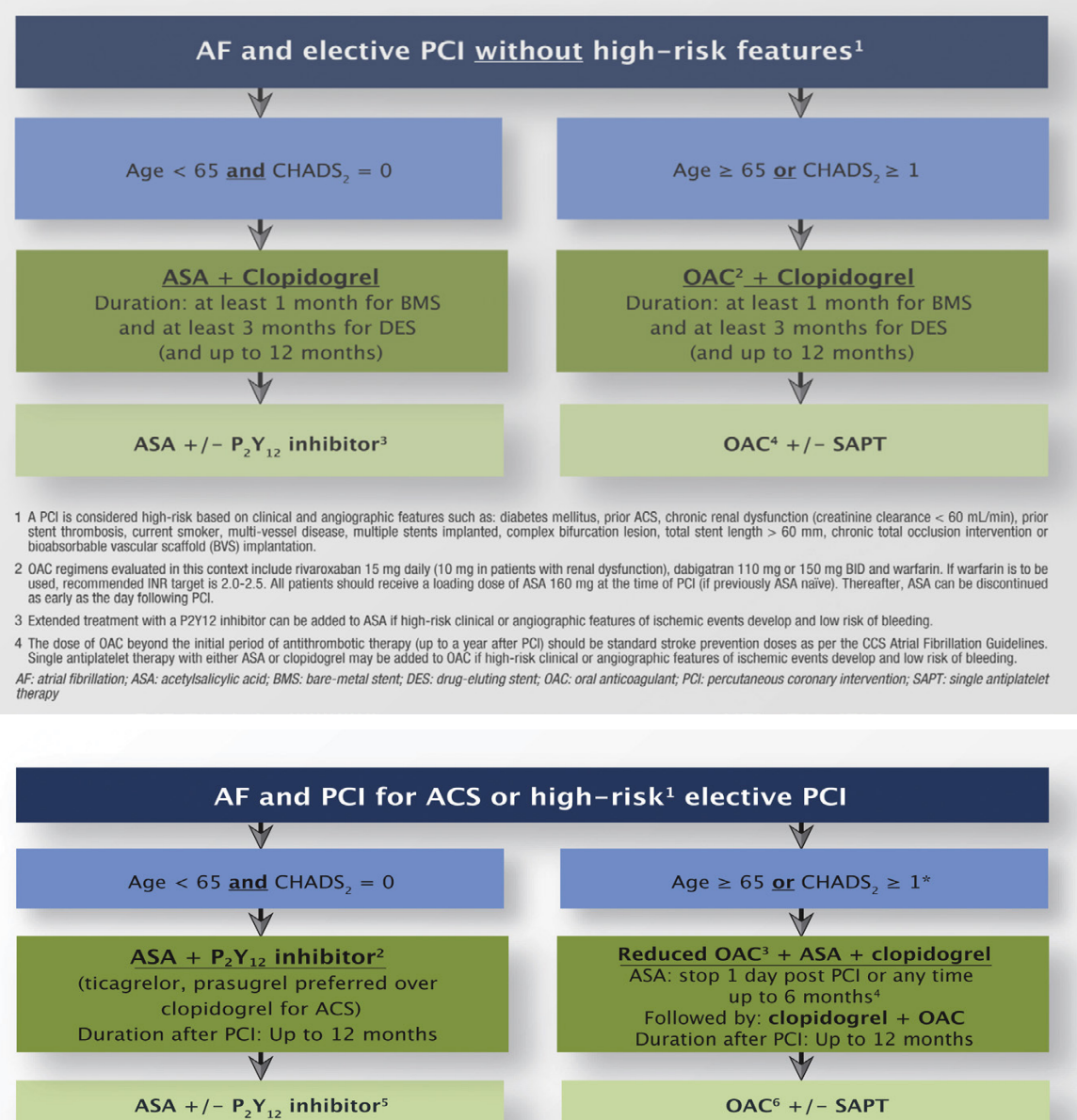

\section{*If $\mathrm{CHADS}_{2}=1$ and $\mathrm{Age}<65$ another option for initial treatment (especially if high-risk for ischemic events) is DAPT alone using ASA+ticagrelor} or ASA+prasugrel, similar to the recommendation for the CHADS $_{2}=0$ patient

1 A PCI is considered high-risk based on clinical and angiographic features such as: diabetes, prior ACS, chronic renal dysfunction (creatinine clearance $<60 \mathrm{~mL} / \mathrm{min}$ ), prior sten thrombosis, current smoker, multi-vessel coronary artery disease, multiple stents implanted, complex bifurcation lesion, total stent length $>60 \mathrm{~mm}$, chronic total occlusion 2 Ticagrelor and prasugrel are recommended in ACS patients, whereas clopidogrel is recommended for elective PCI.

Regimens evaluated in the context of triple therapy include rivaroxaban $2.5 \mathrm{mg}$ BID or warfarin. If warfarin is to be used, recommended INR target is 2.0-2.5. OAC options
evaluated in the context of a dual pathway strategy include rivaroxaban $15 \mathrm{mg}$ daily (plus clopidogrel) or dabigatran $110 \mathrm{mg} / 150 \mathrm{mg}$ BID (plus clopidogrel). 4 DAPT will have been started as part of ACS management or prior to high risk elective PCI. ASA may be discontinued as early as the day following PCI or it can be continued
longer term (eg. 1,3 or maximum 6 months after PCC). The timing of when to discontinue ASA will vary, depending on the individual patient's ischemic and bleeding risk. 5 A P2Y12 inhibitor can be added to ASA if high-risk clinical or angiographic features of ischemic events and low risk of bleeding.

6 The dose of OAC beyond 1 year after PCI should be standard stroke prevention doses as per the CCS Atrial Fibrillation Guidelines. Single antiplatelet therapy with either ASA or

AF: atrial fibrillation; ACS: acute coronary syndrome; ASA: acetylsalicylic acid; OAC: oral anticoagulant; PCl: percutaneous coronary intervention; DAPT: dual antiplatelet therapy;
SAPT: single antiplatelet therapy
FIGURE 9. Recommendations for patients with AF without high-risk features who undergo elective PCI.
FIGURE 10. Recommendations for patients with AF who undergo $\mathrm{PCl}$ for $\mathrm{ACS}$ or high-risk elective $\mathrm{PCl}$.

\section{TABLE 15. Summary and synthesis of guideline, expert consensus documents, and comprehensive review article recommendations} on the management of patients treated with triple therapy.

\section{Recommendations:}

Assess ischemic and bleeding risks using validated risk predictors (e.g., CHA2DS2-VASc, HAS-BLED)

Keep triple therapy duration as short as possible; dual therapy only (oral anticoagulant and clopidogrel) may be considered in select patients

Consider a target INR of 2.0-2.5 when warfarin is used

Clopidogrel is the P2Y12 inhibitor of choice

Use low-dose (\#100 mg daily) aspirin

PPIs should be used in patients with a history of gastrointestinal bleeding and are reasonable to use in patients with increased risk of gastrointestinal bleeding

1. Similar type and duration of DAPT are recommended in male and female patients

2. Similar type and duration of DAPT are recommended in patients with and without diabetes mellitus

3. Patients with prior stent thrombosis, especially in the absence of correctable causes, should receive prolonged DAPT

4. A prolonged DAPT regimen may also be considered in patients with LowerExtremities Artery Disease (LEAD) or who have undergone complex PCI 
TABLE 16. Patients with indication for oral anticoagulation.

\begin{tabular}{|l|}
\hline Recommendations: \\
\hline Compared with OAC therapy alone, the addition of DAPT to OAC therapy results in at least a two-to three-fold increase in bleeding \\
complications
\end{tabular}

A published article in JAMA in 2012 has shown the result of prospective, randomized double-blind, placebo-controlled, multicenter trial in 210 patients who were awaiting surgery and who discontinued DAPT was used to the beneficial effect of intravenous cangrelor as a bridge to fill this time without a DAPT, but further studies on suggesting this strategy in this context are needed for sure.

\section{Conclusion}

It should be kept in mind that the enormous budget, coupled with the great effort of researchers over the past decades, has made the diagnosis and treatment of heart disease the conditions we are in today. On the other hand, for long years, coronary stenting had performed without the use of advanced vascular imaging techniques and causing early and delayed stent failure and thrombosis. Also, nowadays, routine use of vascular imaging to verify the optimal results besides the coronary stenting still performing in a small fraction of patients and limited in some professional centers even in developed countries. Therefore, the possibility of stent failure including thrombosis is a reality in the following years post-procedure such as very late stent thrombosis (even after ten years), especially when we face patients who are candidates for operation and consultants have to discontinue antiplatelet/anticoagulants for any reason. Therefore, we face the risk of myocardial infarction with proven high mortality rate in the pre-operative period, which still requires a great deal of effort so that patients who have avoided the potential risks of myocardial infarction and ischemia due to strenuous efforts before are not easily exposed to an eventful procedure.

\section{Conflict of Interest}

The author declares no conflict of interest.

\section{Funding}

No specific funding was received for this work. 


\section{REFERENCES}

Lloyd-Jones D, Adams RJ, Brown TM, et al. Executive summary: heart disease and stroke statistics-2010 update: a report from the American Heart Association. Circulation. 121, 948-954 (2010).

Mozaffarian D, Benjamin EJ, Arnett DK, et al. Executive summary: heart disease and stroke statistics-2016 update: A report from the American Heart Association. Circulation. 133, 447-454 (2016).

Lopez AD, Mathers CD, Ezzati M, et al. Global and regional burden of disease and risk factors, 2001: systematic analysis of population health data. Lancet. 367, 1747-1757 (2001).

Roger VL, Weston SA, Killian JM, et al. Time trends in the prevalence of atherosclerosis: a population-based autopsy study. Am J Med. 110, 267-273 (2001).

Fabian SG, Carme PS, Roman L, et al. Epidemiology of coronary heart disease and acute coronary syndrome. Ann Transl Med. 4, 256 (2016).

Yusuf S, Reddy S, Ounpuu S, et al. Global burden of cardiovascular diseases: Part II: variations in cardiovascular disease by specific ethnic groups and geographic regions and prevention strategies. Circulation. 104, 2855-2864 (2001).

Sheth T, Nair C, Nargundkar M, et al. Cardiovascular and cancer mortality among Canadians of European, south Asian and Chinese origin from 1979 to 1993: an analysis of 1.2 million deaths. Can Med Assoc J. 161, 132-138 (1999).

Nichols M, Townsend N, Scarborough P, et al. Cardiovascular disease in Europe 2014: epidemiological update. Eur Heart J. 35, 2950-2959 (2014).

Bryant J. Webber. Autopsybased study examines prevalence of atherosclerosis among U.S. service members. JAMA. 308, 2577-2583 (2012).

Joseph A1, Ackerman D, Talley JD, et al. Manifestations of coronary atherosclerosis in young trauma victimsan autopsy study. J Am Coll Cardiol. 22, 459-467 (1993).
Enos, Jr., William, Heart attack prevention. A history of cardiovascular disease epidemiology (1974).

McNamara JJ, Molot MA, Stremple JF, et al. Coronary artery disease in combat casualties in Vietnam. JAMA. 216, 1185-1187 (1971).

Tuzcu EM, Kapadia SR, Tutar E, et al. High prevalence of coronary atherosclerosis in asymptomatic teenagers and young adults evidence from intravascular ultrasound. Circulation. 103, 2705-2710 (2001).

Bild DE, McClelland R, Kaufman JD, et al. Ten-year trends in coronary calcification in individuals without clinical cardiovascular disease in the multi-ethnic study of atherosclerosis. Plos One. 9, 0094916 (2014).

Kumar S, Verma AK, Kumar N, et al. Prevalence of coronary atherosclerosis in different age groups: A postmortem study. Biomedical Research. 24, 139-141 (2013).

Townsend N, Wilson L, Bhatnagar P, et al. Cardiovascular disease in Europe: Epidemiological update 2016. Eur Heart J. 7, 3232-3245 (2016).

Beaglehole R, Reddy S, Leeder SR. Poverty and human development: the global implications of cardiovascular disease. Circulation. 116, 1871-1873 (2007).

Giedrimiene D, King R. Abstract 207: Burden of Cardiovascular Disease (CVD) on economic cost. Comparison of outcomes in US and Europe. Circulation: Cardiovascular Quality and Outcomes. 10, A207 (2017).

Smith SC, Collins A, Ferrari R, et al. Our time: a call to save preventable death from cardiovascular disease (heart disease and stroke). J Am Coll Cardiol. 60, 23432348 (2012).

Maddox TM, Stanislawski MA, Grunwald GK, et al. Nonobstructive coronary artery disease and risk of myocardial infarction. JAMA. 312, 17541763 (2014).

Fleg JL, Forman DE, Berra K, et al. Secondary prevention of atherosclerotic cardiovascular disease in older adults: A scientific statement from the American Heart Association. Circulation. 128, 2422-2446 (2019).

Adjedj J, De Bruyne B, Flore V, et al. Significance of intermediate values of fractional flow reserve in patients with coronary artery disease. Circulation. 133, 502-508 (2016).

Maddox TM, Reid KJ, Spertus JA, et al. Angina at 1 year after myocardial infarction: prevalence and associated findings. Arch Intern Med. 168, 1310 1316 (2008).

Mensah GA, Brown DW. An overview of cardiovascular disease burden in the United States. Health Aff (Millwood). 26, 38-48 (2007).

Thygesen K, Mair J, Giannitsis E, et al. How to use high-sensitivity cardiac troponins in acute cardiac care. European Heart Journal. 33, 2252-2257 (2012).

Rumsfeld JS, Magid DJ, Plomondon $\mathrm{ME}$, et al. Health-related quality of life after percutaneous coronary intervention versus coronary bypass surgery in highrisk patients with medically refractory ischemia. J Am Coll Cardiol. 41, 17321738 (2003).

Rumsfeld JS, MaWhinney S, McCarthy M Jr, et al. Health-related quality of life as a predictor of mortality following coronary artery bypass graft surgery. Participants of the Department of Veterans Affairs cooperative study group on processes, structures, and outcomes of care in cardiac surgery. JAMA. 281, 1298-1303 (1991).

Wiest FC, Bryson CL, Burman M, et al. Suboptimal pharmacotherapeutic management of chronic stable angina in the primary care setting. Am J Med. 117, 234-241 (2004).

Nguyen P, Nag D, Joseph Wu. Sex differences in the diagnostic evaluation of coronary artery disease. J Nucl Cardiol. 18, 144-152 (2011).

Greenland P, Alpert JS, Beller GA, et al. 2010 ACCF/AHA guideline for assessment of cardiovascular risk in asymptomatic adults: a report for the American College of Cardiology Foundation/American Heart Association Task Force on Practice Guideline. Circulation. 122, 584-636 (2010).

Gibbons L, Blair SN, Kohl HW, et al. The safety of maximal exercise testing. Circulation. 80, 846-852 (1989).

Wijns W, Kolh P, Danchin N. Guidelines on myocardial revascularization. The Task Force on 
myocardial revascularization of the European Society of Cardiology (ESC) and the European Association for CardioThoracic Surgery (EACTS). Eur Heart J. 31, 2501-2555 (2014).

Sicari R, Nihoyannopoulos P, Evangelista A, et al. Stress echocardiography expert consensus statement: European Association of Echocardiography (EAE). Eur J Echocardiogr. 9, 415-437 (2008).

Rozanski A, Gransar H, Hayes SW, et al. Temporal trends in the frequency of inducible myocardial ischemia during cardiac stress testing: 1991 to 2009. J Am Coll Cardiol. 61, 1054-1065 (2013).

Taylor AJ, Cerqueira M, Hodgson JM, et al. ACCF/SCCT/ACR/AHA/ ASE/ASNC/NASCI/SCAI/SCMR 2010 appropriate use criteria for cardiac computed tomography. A report of the American College of Cardiology Foundation Appropriate Use Criteria Task Force, the Society of Cardiovascular Computed Tomography, the American College of Radiology, the American Heart Association, the American Society of Echocardiography, the American Society of Nuclear Cardiology, the North American Society for Cardiovascular Imaging, the Society for Cardiovascular Angiography and Interventions, and the Society for Cardiovascular Magnetic Resonance. J Am Coll Cardiol. 56, 18641894 (2010).

Nakanish R, Budoff MJ. Noninvasive FFR derived from coronary CT angiography in the management of coronary artery disease: technology and clinical update. Vasc Health Risk Manag. 12, 269-278 (2016).

McGraw S, DO, Romano S, Jue J, et al. Impact of stress cardiac magnetic resonance imaging on clinical care. $\mathrm{Am} \mathrm{J}$ Cardiol. 118, 924-929 (2016).

Montalescot G, Sechtem U, Achenbach S, et al. 2013 ESC guidelines on the management of stable coronary artery disease. The task force on the management of stable coronary artery disease of the European Society of Cardiology. Eur Heart J. 34, 2949-3003 (2013).

Ford ES, Ajani UA, Croft JB, et al. Explaining the decrease in U.S. deaths from coronary disease, 1980-2000. $N$ Engl J Med. 356, 2388-2398 (2007).
Emond M, Mock MB, Davis KB, et al. Long-term survival of medically treated patients in the Coronary Artery Surgery Study (CASS) Registry. Circulation. 90, 2645-2657 (1994).

Warren SG, Brewer DL, Orgain ES. Long-term propranolol therapy for angina pectoris. Am J Cardiol. 37, 420426 (1976).

Puymirat E, Riant E, Aissaoui N, et al. $\otimes$ blockers and mortality after myocardial infarction in patients without heart failure: multicentre prospective cohort study. BMJ. 354, i480 (2016).

Krikler DM. Calcium antagonists for chronic stable angina pectoris. Am J Cardiol. 59, 95B-100B (1987).

Kannam JP, Gersh BJ, Kaski JC. Nitrates in the management of stable angina pectoris. Up ToDate. (2015).

Wilson SR, Scirica BM, Braunwald E, et al. Efficacy of ranolazine in patients with chronic angina observations from the randomized, double-blind, placebocontrolled MERLIN-TIMI (metabolic efficiency with ranolazine for less ischemia in non-st-segment elevation acute coronary syndromes) 36 Trial. $\mathrm{J} \mathrm{Am}$ Coll Cardiol. 53, 1510-1506 (2009).

Effects of ramipril on cardiovascular and microvascular outcomes in people with diabetes mellitus: results of the HOPE study and MICRO-HOPE substudy. Heart outcomes prevention evaluation study investigators. Lancet. 355, 253-259 (2000).

Diego C, Vila-Corcoles A, Ochoa $\mathrm{O}$, et al. Effects of annual influenza vaccination on winter mortality in elderly people with chronic heart disease. Eur Heart J. 30, 209-16 (2008).

Neumann FJ, Sousa-Uva MM, Ahlsson A, et al. 2018 ESC/ EACTS Guidelines on myocardial revascularization. European Heart Journal. 40, 87-165 (2019).

Head SJ, Kaul S, Mack MJ, et al. The rationale for heart team decision-making for patients with stable, complex coronary artery disease. Eur Heart J. 34, 2510 2518 (2013).

Trikalinos TA, Siebert U, Lau J. Decision-analytic modeling to evaluate benefits and harms of medical tests: uses and limitations. Med Decis Making. 29, 22-29 (2009).
Boden WE, O’Rourke RA, Teo KK, et al. Optimal medical therapy with or without PCI for stable coronary disease. N Engl J Med. 356, 1503-1516 (2007).

Frye RL, August P, Brooks MM, et al. A randomized trial of therapies for type 2 diabetes and coronary artery disease. $N$ Engl J Med. 360, 2503-2515 (2009).

Dzavik V, Ghali WA, Norris C, et al. Long-term survival in 11,661 patients with multivessel coronary artery disease in the era of stenting: a report from the Alberta Provincial Project for Outcome Assessment in Coronary Heart Disease (APPROACH) Investigators. Am Heart J. 142, 119-126 (2001).

Jones RH, Kesler K, Phillips HR III, et al. Long-term survival benefits of coronary artery bypass grafting and percutaneous transluminal angioplasty in patients with coronary artery disease. $J$ Thorac Cardiovasc Surg. 111, 1013-1025 (1996).

Smith PK, Califf RM, Tuttle RH, et al. Selection of surgical or percutaneous coronary intervention provides differential longevity benefit. Ann Thorac Surg. 82, 1420-1428 (2006).

Cecil WT, Kasteridis P, Barnes JW Jr, et al. A meta-analysis update: percutaneous coronary interventions. Am J Manag Care. 14, 521-528 (2008).

Katritsis DG, Ioannidis JP. Percutaneous coronary intervention versus conservative therapy in nonacute coronary artery disease: a meta-analysis. Circulation. 111, 2906-2912 (2005).

Schomig A, Mehilli J, de WA, et al. A meta-analysis of 17 randomized trials of a percutaneous coronary intervention-based strategy in patients with stable coronary artery disease. J Am Coll Cardiol. 52, 894904 (2008).

Katritsis DG, Ioannidis JP. PCI for stable coronary disease. $N$ Engl J Med. 357, 414-419 (2007).

Trikalinos TA, Siebert U, Lau J. Decision-analytic modeling to evaluate benefits and harms of medical tests: uses and limitations. Med Decis Making. 29, e22-e29 (2009).

Sedlis SP, Hartigan PM, Teo KK, et al. Effect of PCI on long-term survival in patients with stable ischemic heart disease. N Engl J Med. 373, 1937-1946 (2015). 
Fihn SD, Gardin JM, Abrams J, et al. 2012 ACCF/AHA/ACP/AATS/ PCNA/SCAI/STS Guideline for the diagnosis and management of patients with stable ischemic heart disease: a report of the American College of Cardiology Foundation/American Heart Association Task Force on Practice Guidelines, and the American College of Physicians, American Association for Thoracic Surgery, Preventive Cardiovascular Nurses Association, Society for Cardiovascular Angiography and Interventions, and Society of Thoracic Surgeons. J Am Coll Cardiol. 60, 44-164 (2012).

Poses RM, Krueger JI, Sloman $S$, et al. Physicians' judgments of survival after medical management and mortality risk reduction due to revascularization procedures for patients with coronary artery disease. Chest. 122, 122-133 (2002).

Windecker S, Stortecky S, Stefanini $\mathrm{GG}$, et al. Revascularisation versus medical treatment in patients with stable coronary artery disease: Network meta-analysis. BMJ 348, 3859 (2014).

De Bruyne B, Pijls NH, Kalesan $B$, et al. FAME 2 Trial Investigators. Fractional flow reserve-guided PCI versus medical therapy in stable coronary disease. N Engl J Med. 367, 991-1001 (2012).

Serruys PW, Morice MC, Kappetein PA, et al. Percutaneous coronary intervention versus coronary-artery bypass grafting for severe coronary artery disease. $N$ Engl J Med. 360, 961972 (2009).

Farooq V, van Klaveren D, Steyerberg EW, et al. Anatomical and clinical characteristics to guide decision making between coronary artery bypass surgery and percutaneous coronary intervention for individual patients: development and validation of SYNTAX score II. Lancet. 381, 639650 (2013).

Pittman MA, Margolin FS. Community health. Crossing the quality chasm: steps you can take. Trustee. 54, 30-32 (2001).

Carson P, Wertheimer J, Miller A, et al. The STICH trial (Surgical Treatment for Ischemic Heart Failure): mode-ofdeath results. JACC Heart Fail. 1, 400-
408 (2013).

Velazquez EJ, Lee KL, Jones RH, et al. STITCHES Investigators. Coronaryartery bypass surgery in patients with ischemic cardiomyopathy. $N$ Engl J Med. 374, 1511-1520 (2016).

Hueb W, Lopes N, Gersh BJ, et al. Ten-year follow-up survival of the Medicine, Angioplasty, or Surgery Study (MASS II): a randomized controlled clinical trial of 3 therapeutic strategies for multivessel coronary artery disease. Circulation. 122, 949957 (2010).

Kappetein AP, Feldman TE, Mack MJ, et al. Comparison of coronary bypass surgery with drug-eluting stenting for the treatment of left main and/or three-vessel disease: 3-year follow-up of the SYNTAX trial. Eur Heart J. 32, 2125-2134 (2011).

Bonow RO, Maurer G, Lee KL, et al. Myocardial viability and survival in ischemic left ventricular dysfunction. $N$ Engl J Med. 364, 1617-1625 (2011).

Allman KC, Shaw LJ, Hachamovitch R, et al. Myocardial viability testing and impact of revascularization on prognosis in patients with coronary artery disease and left ventricular dysfunction: A meta-analysis. J Am Coll Cardiol. 39, 1151-1158 (2002).

Ling LF, Marwick TH, Flores DR, et al. Identification of therapeutic benefit from revascularization in patients with left ventricular systolic dysfunction: Inducible ischemia versus hibernating myocardium. Circ Cardiovasc Imaging. 6, 363-372 (2013).

Neumann FJ, Sousa-Uva M, Ahlsson A, et al. 2018 ESC/ EACTS Guidelines on myocardial revascularization. Eur Heart J. 40, 87165 (2019).

Farooq V, Serruys PW, GarciaGarcia HM, et al. The negative impact of incomplete angiographic revascularization on clinical outcomes and its association with total occlusions: the SYNTAX (Synergy between Percutaneous Coronary Intervention with Taxus and Cardiac Surgery) trial. $J$ Am Coll Cardiol. 61, 282-294 (2013).

Shaw LJ, Berman DS, Maron DJ, et al. Optimal medical therapy with or without percutaneous coronary intervention to reduce ischemic burden: Results from the Clinical Outcomes Utilizing Revascularization and Aggressive Drug Evaluation (COURAGE) trial nuclear substudy. Circulation. 117, 1283-1291 (2008).

Farkouh ME, Domanski M, Sleeper LA, et al. Strategies for multivessel revascularization in patients with diabetes. $N$ Engl J Med. 367, 23752384 (2012).

Roffi M, Patrono C, Collet JP, et al. 2015 ESC Guidelines for the management of acute coronary syndromes in patients presenting without persistent STsegment elevation: task force for the management of acute coronarysyndromes in patients presenting without persistent stsegment elevation of the European Society of Cardiology (ESC). Eur Heart J. 37, 267-315 (2016).

Yusuf S, Mehta SR, Chrolavicius $S$, et al. Comparison of fondaparinux and enoxaparin in acute coronary syndromes. N Engl J Med. 354, 14641476 (2006).

Simoons ML, Bobbink IW, Boland J, et al. A dose-finding study of fondaparinux in patients with nonST-segment elevation acute coronary syndromes: the pentasaccharide in unstable angina (PENTUA) study. $J$ Am Coll Cardiol. 43, 2183-2190 (2004)

Bavry AA, Kumbhani DJ, Rassi $A N$, et al. Benefit of early invasive therapy in acute coronary syndromes: a meta-analysis of contemporary randomized clinical trials. J Am Coll Cardiol. 48, 1319-1325 (2006).

Pijls NH, Tanaka N, Fearon WF. Functional assessment of coronary stenosis: can we live without it? Eur Heart J. 34,1335-1344 (2013).

Martensson S, Gyrd-Hansen D, Prescott E, et al. Trends in time to invasive examination and treatment from 2001 to 2009 in patients admitted first time with non-ST elevation myocardial infarction or unstable angina in Denmark. BMJ. 4, e00405 (2014)

Yusuf S, Zhao F, Mehta SR, et al. Effects of clopidogrel in addition to aspirin in patients with acute coronary syndromes without ST-segment 
elevation. $N$ Engl J Med. 345, 494-502 (2001).

Wallentin L, Becker RC, Budaj A, et al. Ticagrelor versus clopidogrel in patients with acute coronary syndromes. N Engl J Med. 361, 1045-1057 (2009).

Tamis-Holland JE, Jneid H, Reynolds $\mathrm{HR}$, et al. Contemporary diagnosis and management of patients with myocardial infarction in the absence of obstructive coronary artery disease: a scientific statement from the American Heart Association. Circulation. 139, e891-e908 (2019).

Pathik B, Raman B, Mohd Amin $\mathrm{NH}$, et al. Troponin-positive chest pain with unobstructed coronary arteries: incremental diagnostic value of cardiovascular magnetic resonance imaging. Eur Heart J Cardiovasc Imaging. 17, 1146-1152 (2016).

Thygesen K, Alpert JS, Jaffe AS, et al. Third universal definition of myocardial infarction. Eur Heart J. 33, 2551-2567 (2012).

Armstrong PW, Gershlick AH, Goldstein P, et al. Fibrinolysis or primary PCI in ST-segment elevation myocardial infarction. N Engl J Med. 368, 13791387 (2013).

Romagnoli E, Biondi-Zoccai G, Sciahbasi A, et al. Radial versus femoral randomized investigation in ST-segment elevation acute coronary syndrome: the RIFLE-STEACS (Radial Versus Femoral Randomized Investigation in ST-Elevation Acute Coronary Syndrome) study. J Am Coll Cardiol. 60, 2481-2489 (2012).

Nordmann AJ, Hengstler P, Harr T, et al. Clinical outcomes of primary stenting versus balloon angioplasty in patients with myocardial infarction: a metaanalysis of randomized controlled trials. Am J Med. 116, 253-262 (2004).

Raber L, Kelbaek H, Ostojic M, et al. Effect of Biolimus-eluting stents with biodegradable polymer $v$ s. bare-metal stents on cardiovascular events among patients with acute myocardial infarction: the comfortable AMI randomized trial. JAMA. 308, 777-787 (2012).

Sabate M, Cequier A, Iniguez A, et al. Everolimus-eluting stent versus bare-metal stent in ST-segment elevation myocardial infarction
(EXAMINATION): 1 year results of a randomised controlled trial. Lancet. 380, 1482-1490 (2012).

Gershlick AH, Khan JN, Kelly DJ, et al. Randomized trial of complete versus lesion-only revascularization in patients undergoing primary percutaneous coronary intervention for STEMI and multivessel disease: the CvLPRIT trial. $J$ Am Coll Cardiol. 65, 963-972 (2015).

Engstrom T, Kelbaek H, Helqvist $S$, et al. Complete revascularisation versus treatment of the culprit lesion only in patients with ST-segment elevation myocardial infarction and multivessel disease (DANAMI-3-PRIMULTI): an open-label randomized controlled trial. Lancet. 386, 665-671 (2015).

Frobert O, Lagerqvist B, Olivecrona GK, et al. Thrombus aspiration during STsegment elevation myocardial infarction. N Engl J Med. 369, 15871597 (2013).

Lagerqvist B, Frobert O, Olivecrona GK, et al. Outcomes 1 year after thrombus aspiration for myocardial infarction. N Engl J Med. 371, 11111120 (2014).

Carrick D, Oldroyd KG, McEntegart $\mathrm{M}$, et al. A randomized trial of deferred stenting versus immediate stenting to prevent no- or slow-reflow in acute STsegment elevation myocardial infarction (DEFER-STEMI). J Am Coll Cardiol. 63, 2088-2098 (2014).

Belle L, Motreff P, Mangin L, et al. Comparison of immediate with delayed stenting using the minimalist immediate mechanical intervention approach in acute ST-segment-elevation myocardial infarction: the MIMI Study. Circ Cardiovasc Interv. 9, e003388 (2016)

Zijlstra F, Hoorntje JC, de Boer $\mathrm{MJ}$, et al. Long-term benefit of primary angioplasty as compared with thrombolytic therapy for acute myocardial infarction. N Engl J Med. 341, 1413-1419 (1999).

Keeley EC, Boura JA, Grines CL. Primary angioplasty versus intravenous thrombolytic therapy for acute myocardial infarction: a quantitative review of 23 randomised trials. Lancet. 361, 13-20 (2003).

Widimsky P, Budesinsky T, Vorac D, et al. Long-distance transport for primary angioplasty vs immediate thrombolysis in acute myocardial infarction. Final results of the randomized national multicentre trial-PRAGUE-2. Eur Heart J. 24, 94104 (2003).

Andersen HR, Nielsen TT, Rasmussen K, et al. A comparison of coronary angioplasty with fibrinolytic therapy in acute myocardial infarction. $N$ Engl J Med. 349, 733-742 (2003).

Kelbaek H, Hofsten DE, Kober $\mathrm{L}$, et al. Deferred versus conventional stent implantation in patients with STsegment elevation myocardial infarction (DANAMI 3-DEFER): an open-label, randomized controlled trial. Lancet. 387, 2199-2206 (2016).

Bueno H, Betriu A, Heras M, et al. Primary angioplasty vs. fibrinolysis in very old patients with acute myocardial infarction: TRIANA (TRatamiento del Infarto Agudo de miocardio eN Ancianos) randomized trial and pooled analysis with previous studies. Eur Heart J. 32, 51-60 (2011).

Patel MR, Smalling RW, Thiele H, et al. Intra-aortic balloon counterpulsation and infarct size in patients with acute anterior myocardial infarction without shock: the CRISP AMI randomized trial. JAMA. 306, 1329-1337 (2011).

Thiele H, Zeymer U, Neumann FJ, et al. Intraaortic balloon support for myocardial infarction with cardiogenic shock. N Engl J Med. 367, 1287-1296 (2012).

Gierlotka M, Gasior M, Wilczek K, et al. Reperfusion by primary percutaneous coronary intervention in patients with ST-segment elevation myocardial infarction within 12 to 24 hours of the onset of symptoms (from a prospective national observational study [PL-ACS]). Am J Cardiol. 107, 501-508 (2011).

Lyon AR, Bossone E, Schneider $\mathrm{B}$, et al. Current state of knowledge on Takotsubo syndrome: A position statement from the taskforce on takotsubo syndrome of the heart failure Association of the European Society of Cardiology. Eur J Heart Fail. 18, 8-27 (2016).

Templin C, Ghadri JR, Diekmann $\mathrm{J}$, et al. Clinical features and outcomes of takotsubo (stress) cardiomyopathy. $N$ Engl J Med. 373, 929-938 (2015). 
Medeiros K, O'Connor MJ, Baicu CF, et al. Systolic and diastolic mechanics in stress cardiomyopathy. Circulation. 129, 1659-1667 (2014).

Pasupathy S, Air T, Dreyer RP, et al. Systematic review of patients presenting with suspected myocardial infarction and nonobstructive coronary arteries. Circulation. 131, 861-870 (2015).

Navarese EP, Andreotti F, Schulze $\mathrm{V}$, et al. Optimal duration of dual antiplatelet therapy after percutaneous coronary intervention with drug-eluting stents: meta-analysis of randomized controlled trials. BMJ. 16, 350 (2015).

Pedersen F, Butrymovich V, Kelbaek $\mathrm{H}$, et al. Short- and long-term cause of death in patients treated with primary PCI for STEMI. J Am Coll Cardiol. 64, 2101-2108 (2014).

Kristensen SD, Laut KG, Fajadet J, et al. Reperfusion therapy for ST elevation acute myocardial infarction 2010. Eur Heart J. 35, 1957-1970 (2014).

Anderson L, Oldridge N, Thompson DR, et al. Exercise-based cardiac rehabilitation for coronary heart disease: Cochrane systematic review and meta-analysis. J Am Coll Cardiol. 67, 1-12 (2016).

Bangalore S, Steg G, Deedwania P, et al. Beta-blocker use and clinical outcomes in stable outpatients with and without coronary artery disease. JAMA. 308, 1340-1349 (2012).

Baigent C, Blackwell L, Collins $\mathrm{R}$, et al. Aspirin in the primary and secondary prevention of vascular disease: collaborative meta-analysis of individual participant data from randomised trials. Lancet. 373, 18491860 (2009).

Sabatine MS, Cannon CP, Gibson $\mathrm{CM}$, et al. Addition of clopidogrel to aspirin and fibrinolytic therapy for myocardial infarction with ST-segment elevation. N Engl J Med. 352, 11791189 (2005).

Bonaca MP, Bhatt DL, Cohen $\mathrm{M}$, et al. Long-term use of ticagrelor in patients with prior myocardial infarction. $N$ Engl J Med. 372, 17911800 (2015).

Mauri L, Kereiakes DJ, Yeh RW, et al. Twelve or 30 months of dual antiplatelet therapy after drug-eluting stents. $N$ Engl J Med. 371, 2155-2166 (2014).

Chang AM, Shofer FS, Tabas JA, et al. Lack of association between left bundle-branch block and acute myocardial infarction in symptomatic ED patients. Am J Emerg Med. 27, 916921 (2009).

Madias JE. The nonspecificity of ST-segment elevation > or $=5.0$ $\mathrm{mm}$ in $\mathrm{V} 1-\mathrm{V} 3$ in the diagnosis of acute myocardial infarction in the presence of ventricular paced rhythm. $J$ Electrocardiol. 37, 135-139 (2004).

Widimsky P, Rohac F, Stasek J, et al. Primary angioplasty in acute myocardial infarction with right bundle branch block: should new onset right bundle branch block be added to future guidelines as an indication for reperfusion therapy? Eur Heart J. 33, 86-95 (2012).

Rokos IC, Farkouh ME, Reiffel $\mathrm{J}$, et al. Correlation between index electrocardiographic patterns and preintervention angiographic findings: insights from the HORIZONS-AMI trial. Catheter Cardiovasc Interv. 79, 1092-1098 (2012).

Stribling WK, Kontos MC, Abbate A, et al. Left circumflex occlusion in acute myocardial infarction (from the National Cardiovascular Data Registry). Am J Cardiol. 108, 959-963 (2011).

Yan AT, Yan RT, Kennelly BM, et al. Relationship of ST elevation in lead $a V R$ with angiographic findings and outcome in non-ST elevation acute coronary syndromes. Am Heart J. 154, 71-78 (2007).

Vaahersalo J, Hiltunen P, Tiainen $\mathrm{M}$, et al. Therapeutic hypothermia after out-of-hospital cardiac arrest in Finnish intensive care units: the FINNRESUSCI study. Intensive Care Med. 39, 826-837 (2013).

Zeymer U, Hohlfeld T, Vom Dahl $\mathrm{J}$, et al. Prospective, randomised trial of the time dependent antiplatelet effects of $500 \mathrm{mg}$ and $250 \mathrm{mg}$ acetylsalicylic acid i. v. and $300 \mathrm{mg} \mathrm{p.} \mathrm{o.} \mathrm{in} \mathrm{ACS}$ (ACUTE). Thromb Haemost. 117, 625635 (2017).

Wiviott SD, Braunwald E, McCabe $\mathrm{CH}$, et al. Prasugrel versus clopidogrel in patients with acute coronary syndromes. N Engl J Med. 357, 20012015 (2007).

Mehta SR, Tanguay JF, Eikelboom JW, et al. Double-dose versus standarddose clopidogrel and high-dose versus low-dose aspirin in individuals undergoing percutaneous coronary intervention for acute coronary syndromes (CURRENT-OASIS 7): a randomised factorial trial. Lancet. 376, 1233-1243 (2010).

Koul S, Smith JG, Schersten F, et al. Effect of upstream clopidogrel treatment in patients with ST-segment elevation myocardial infarction undergoing primary percutaneous coronary intervention. Eur Heart J. 32, 2989-2997 (2011).

Dorler J, Edlinger M, Alber HF, et al. Clopidogrel pre-treatment is associated with reduced in-hospital mortality in primary percutaneous coronary intervention for acute STelevation myocardial infarction. Eur Heart J. 32, 2954-1961 (2011).

Zeymer U, Arntz HR, Mark B, et al. Efficacy and safety of a high loading dose of clopidogrel administered prehospitally to improve primary percutaneous coronary intervention in acute myocardial infarction: the randomized CIPAMI trial. Clin Res Cardiol. 101, 305-312 (2012).

Harrington RA, Stone GW, McNulty S, et al. Platelet inhibition with cangrelor in patients undergoing PCI. N Engl J Med. 361, 2318-2329 (2009).

Bhatt DL, Stone GW, Mahaffey $\mathrm{KW}$, et al. Effect of platelet inhibition with cangrelor during PCI on ischemic events. N Engl J Med. 368, 1303-1313 (2013).

Friedland S, Eisenberg MJ, Shimony A. Meta-analysis of randomized controlled trials of intracoronary versus intravenous administration of glycoprotein IIb/ IIIa inhibitors during percutaneous coronary intervention for the acute coronary syndrome. Am J Cardiol. 108, 1244-1251 (2011).

Silvain J, Beygui F, Barthelemy O, et al. Efficacy and safety of enoxaparin versus unfractionated heparin during the percutaneous coronary intervention: 
systematic review and meta-analysis. BMJ. 344, e553 (2012).

Capodanno D, Gargiulo G, Capranzano $\mathrm{P}$, et al. Bivalirudin versus heparin with or without glycoprotein IIb/ IIIa inhibitors in patients with STEMI undergoing primary PCI: An updated meta-analysis of 10,350 patients from five randomized clinical trials. Eur Heart J Acute Cardiovasc Care. 5, 253-262 (2016).

Yusuf S, Mehta SR, Chrolavicius S, et al. Effects of fondaparinux on mortality and reinfarction in patients with acute STsegment elevation myocardial infarction: the OASIS-6 randomized trial. JAMA. 295, 1519-1530 (2006).

Fibrinolytic Therapy Trialists' (FTT) Collaborative Group. Indications for fibrinolytic therapy in suspected acute myocardial infarction: collaborative overview of early mortality and major morbidity results from all randomized trials of more than 1000 patients. Lancet. 343, 311-322 (1994).

Morrison LJ, Verbeck PR, McDonald AC, et al. Mortality and prehospital thrombolysis for acute myocardial infarction: a meta-analysis. JAMA. 283, 2686-2692 (2000).

Bjorklund E, Stenestrand U, Lindback J, et al. Prehospital thrombolysis delivered by paramedics is associated with reduced time delay and mortality in ambulance-transported reallife patients with STelevation myocardial infarction. Eur Heart J. 27, 1146-1152 (2006).

The GUSTO Investigators. An international randomized trial comparing four thrombolytic strategies for acute myocardial infarction. N Engl J Med. 329, 673-682 (1993).

Giraldez RR, Nicolau JC, Corbalan $\mathrm{R}$, et al. Enoxaparin is superior to unfractionated heparin in patients with ST elevation myocardial infarction undergoing fibrinolysis regardless of the choice of lytic: an ExTRACT-TIMI 25 analysis. Eur Heart J. 28, 1566-1573 (2007).

White HD. Hirulog and Early Reperfusion or Occlusion (HERO)-2 trial investigators. Thrombin-specific anticoagulation with bivalirudin versus heparin in patients receiving fibrinolytic therapy for acute myocardial infarction. Lancet. 358, 1855-1863 (2001).

Fernandez-Aviles F, Alonso JJ, CastroBeiras A, et al. Routine invasive strategy within 24 hours of thrombolysis versus ischaemia-guided conservative approach for acute myocardial infarction with ST-segment elevation (GRACIA-1): a randomised controlled trial. Lancet. 364, 1045-1053 (2004).

Madan M, Halvorsen S, Di Mario C, et al. Relationship between time to invasive assessment and clinical outcomes of patients undergoing an early invasive strategy after fibrinolysis for ST-segment elevation myocardial infarction: a patient- level analysis of the randomized early routine invasive clinical trials. JACC Cardiovasc Interv. 8, 166-174 (2015).

Gershlick AH, Stephens-Lloyd A, Hughes $S$, et al. Rescue angioplasty after failed thrombolytic therapy for acute myocardial infarction. $N$ Engl J Med. 353, 2758-2768 (2005).

Hochman JS, Sleeper LA, White HD, et al. One-year survival following early revascularization for cardiogenic shock. JAMA. 285, 190-192 (2001).

Hochman JS, Sleeper LA, Webb JG, et al. Should We Emergently Revascularize Occluded Coronaries for Cardiogenic Shock. N Engl J Med. 341, 625-634 (1999).

Levine NG, Bates ER, Bittl JA, et al. Smith Jr. 2016 ACC/AHA guideline focused update on duration of dual antiplatelet therapy in patients with coronary artery disease; A Report of the American College of Cardiology/ American Heart Association Task Force on Clinical Practice Guidelines. J Amer Coll Card. 68 (2016).

Angiolillo DJ, Firstenberg MS, Price $\mathrm{MJ}$, et al. Bridging anti-platelet therapy with the intravenous agent cangrelor in patients undergoing cardiac surgery. JAMA. 307, 265-274 (2012). 